\title{
Cash-in-the-Market Pricing and Optimal Resolution of Bank Failures ${ }^{1}$
}

\author{
Viral V. Acharya ${ }^{2}$ \\ London Business School and CEPR \\ Tanju Yorulmazer ${ }^{3}$ \\ Bank of England
}

J.E.L. Classification: G21, G28, G38, E58, D62.

Keywords: Bailouts, Systemic risk, Banking crises,

Time inconsistency, Too many to fail, Herding, Lender of last resort

This Draft: May, 2006

\begin{abstract}
${ }^{1}$ We are grateful to Mark Flannery, Douglas Gale, Andrew Gracie, Celine Gondat-Larralde, Denis Gromb, Jose Liberti, Erlend Nier, Sypros Pagratis, Enrico Perotti, Alan Sheppard, Hyun Shin, Raghu Sundaram, Lucy White and Lea Zicchino for useful discussions. We would like to thank seminar participants at London Business School, University of Vienna, Bank of England, Cass Business School at the City University of London, Financial Stability Framework Group at the Bank of England, Judge Institute of Management at Cambridge, Norwegian School of Management, Tilburg University and University of Amsterdam and participants of the Financial Fragility, Bank Regulation Conference at the Bank of Portugal, and two anonymous referees for useful comments. All errors remain our own.

${ }^{2}$ Contact: Department of Finance, London Business School, Regent's Park, London - NW1 4SA, England. Tel: +44 (0)20 72625050 Fax: +44 (0)20 77243317 e-mail: vacharya@london.edu. Acharya is also a Research Affiliate of the Centre for Economic Policy Research (CEPR).

${ }^{3}$ Contact: FIRD HO-3, Bank of England, Threadneedle Street, London, EC2R 8AH, Tel: +44 (0) 2076013198 Fax: +44 (0) 2076013217 e-mail: Tanju.Yorulmazer@bankofengland.co.uk.
\end{abstract}




\title{
Cash-in-the-Market Pricing and Optimal Resolution of Bank Failures
}

\begin{abstract}
As the number of bank failures increases, the set of assets available for acquisition by the surviving banks enlarges but the total amount of available liquidity within the surviving banks falls. This results in "cash-in-the-market" pricing for liquidation of banking assets. At a sufficiently large number of bank failures, and in turn, at a sufficiently low level of asset prices, there are too many banks to liquidate and inefficient users of assets who are liquidity-endowed may end up owning the liquidated assets. In order to avoid this allocation inefficiency, it may be ex-post optimal for the regulator to bail out some failed banks. We show however that there exists a liquidity provision policy involving regulatory assistance to surviving banks in the purchase of failed banks that is ex-post equivalent to the bailout policy from a social welfare standpoint. Crucially, the liquidity provision policy gives banks incentives to differentiate, rather than to herd, makes aggregate banking crises less likely, and, thereby dominates the bailout policy from an ex-ante standpoint.
\end{abstract}

J.E.L. Classification: G21, G28, G38, E58, D62.

Keywords: Bailouts, Systemic risk, Banking crises, Time inconsistency, Too many to fail, Herding, Lender of last resort 


\section{Introduction}

The wide-spread belief that rescuing troubled banks can create moral hazard and can give banks incentives to take excessive risk dates back to Bagehot (1873): "Any aid to a present bad bank is the surest mode of preventing the establishment of a good bank." However, empirical evidence suggests that regulatory actions taken in response to banking problems vary significantly. In many episodes, actions taken by regulators appear to depend on whether the problems arise from idiosyncratic reasons specific to particular institutions or from aggregate reasons with potential threats to the whole system, as documented in Santomero and Hoffman (1999) and Kasa and Spiegel (2003). Hoggarth, Reidhill and Sinclair (2004) also study resolution policies adopted in 33 banking crises over the world during 1977-2002. They document that when faced with individual bank failures authorities have usually sought a private-sector resolution where the losses have been passed onto existing shareholders, managers and sometimes uninsured creditors, but not to taxpayers. However, government involvement has been an important feature of the resolution process during systemic crises: At early stages, liquidity support from central banks and blanket government guarantees have been granted, usually at a cost to the budget; bank liquidations have been very rare and creditors have rarely made losses.

We argue in this paper that this difference in regulatory actions arises from the fact that resolution options open for an isolated failure of a single institution are different from those available when facing a systemic failure. When only a few banks fail, these banks can be acquired by the surviving banks. However, regulators cannot commit not to intervene when the crisis is systemic. In particular, for a large number of failures, the liquidity of surviving banks enables them to acquire all failed banks only at fire-sale prices. ${ }^{1}$ The resulting "cashin-the-market" pricing, as in Allen and Gale (1994, 1998), makes it more likely that investors outside the banking sector, who are liquidity-endowed but potentially not the most efficient users of these assets, will end up purchasing some failed banks' assets.

Thus, when the banking crisis is systemic in nature, there are "too many (banks) to liquidate" and bailing out some of the failed banks may be optimal in order to avoid allocation inefficiencies. However, this ex-post optimal bailout policy may be sub-optimal from an exante standpoint, for example, because it induces banks to herd by lending to similar industries or betting on common risks such as interest and mortgage rates, in order to increase the likelihood of being bailed out. This in turn increases the ex-ante likelihood of experiencing systemic banking crises. Can other regulatory options such as the provision of liquidity mitigate this time-inconsistency problem? We propose a novel liquidity provision policy that

\footnotetext{
${ }^{1}$ This effect is akin to the industry-equilibrium hypothesis of Shleifer and Vishny (1992) who argue that when industry peers of a firm in distress are financially constrained, the peers may not be able to pay a price for assets of the distressed firm that equals the value of these assets to them.
} 
involves assisting surviving banks in their purchase of failed banks, that is equivalent ex post to the bailout policy, and, that gives banks incentives to differentiate, rather than to herd.

We formalize these ideas in a framework wherein the ex-ante and the ex-post optimal regulatory policies and the cash-in-the-market pricing are endogenously derived. We consider a two-period model with $n$ banks, a regulator, and outside investors who could purchase banking assets were they to be liquidated. Examining a setting with an arbitrary number of banks enables us to explore the richness of the cash-in-the-market price function. The regulator adopts policies to resolve bank failures with the objective of maximizing the total output generated by the banking sector net of any costs associated with the adopted policies.

We consider the following regulatory policies: Failed banks may be closed, in which case their assets are sold to surviving banks and outsiders at market-clearing prices, or failed banks are bailed out, in which case their owners are allowed to continue operating the banks. The regulator may also provide liquidity to the various players - failed banks, surviving banks, and outsiders. For simplicity, we assume that deposits are fully insured (at least in the first period). The immediacy of funds required for deposit insurance, net of the proceeds received from liquidating the failed banks and net of liquidity provided to the system during failure resolution, entails fiscal costs for the regulator. The regulatory policies are rationally anticipated by banks and depositors.

Three central assumptions drive our results: (i) banks have access to limited liquidity in particular, we assume that surviving banks only have their first-period profits to acquire the failed banks' assets (we relax this assumption later and allow pledgeability of future cash flows), (ii) banks are more efficient users of banking assets than outsiders as long as bank owners take good projects, ${ }^{2}$ and (iii) there is a possibility of moral hazard in that bank owners derive private benefits from bad projects; hence, banks take good projects only if bank owners retain a large enough share in bank profits. ${ }^{3}$

If the return from the first-period investment of the bank is low, then the bank is in default. The surviving banks, if any, use their first-period profits to purchase failed banks' assets. Up to a critical number of bank failures, liquidity with the surviving banks is enough to purchase all the banking assets at their "fundamental" price: surviving banks compete with each other and their surplus is eroded to zero. Beyond this critical number of failures, additional assets cannot be absorbed by the available liquidity of surviving banks at the fundamental price. Thus, the market-clearing price declines with each additional failure. Under assumption (ii),

\footnotetext{
${ }^{2}$ James (1991) studies the losses from bank failures in the United States during the period 1985 through mid-year 1988, and documents that "there is significant going concern value that is preserved if the failed bank is sold to another bank (a "live bank" transaction) but is lost if the failed bank is liquidated by the Federal Deposit Insurance Corporation (FDIC)."

${ }^{3}$ For detailed evidence on large inside ownership of banks around the world and its role in alleviating moral hazard problems, see Caprio, Laeven and Levine (2005).
} 
outsiders are not as efficient users of banking assets as the surviving banks. Hence, they do not enter the market unless prices fall sufficiently. In other words, there is limited market participation. If the price declines sufficiently, then the liquidity-endowed outsiders enter the market and purchase some of the assets. This gives rise to an allocation inefficiency.

The regulator decides whether to allow a private-sector resolution, that is, to let the surviving banks and/or outsiders purchase failed banks' assets, or to intervene. We first consider intervention in the form of bailing out some or all of the failed banks. In a bailout, a failed bank is not liquidated and its existing owners are allowed to continue operating the bank. Bailouts are thus associated with an opportunity cost for the regulator: the regulator incurs a higher fiscal cost to pay off the promised deposits since no proceeds are collected through asset sales. Since bailouts are costly, the regulator does not intervene as long as failed banks are sold to the surviving banks. However, when asset prices decline sufficiently, it is optimal for the regulator to prevent sales to outsiders by bailing out banks until the fiscal cost of a bailout exceeds the misallocation cost from liquidating the marginal bank to outsiders.

With limited outsider funds, when the number of failures is sufficiently large, even the participation of outsiders in the market for asset sales is not enough to sustain the price at the threshold value of outsiders and there is a further decline in the price as the number of failures increase. In this range, the entire liquidity in the market, that is, all funds with the surviving banks and the outsiders, are collected through the sale of failed banks. If the regulator decides to bail out a bank in these cases, the proceeds from the asset sale are not affected and bailouts do not entail any additional fiscal costs. Thus, the regulator bails out more failed banks and prices are sustained at the threshold level for outsiders. Crucially, the states where the number of failures is high are always associated with welfare losses - either fiscal costs through bailouts or misallocation costs through liquidations to outsiders.

We show that there exists a liquidity provision policy that is ex-post equivalent in welfare terms to this bailout policy. It is trivially sub-optimal to provide liquidity to a bailed-out bank, and due to their relative lack of expertise, it is also sub-optimal to provide liquidity to outsiders. However, liquidity provision of a specific form to the surviving banks can do as well as bailouts. Intuitively, bailouts become ex-post optimal when the price of failed banking assets falls sufficiently to elicit participation of outsiders in asset sales. The lack of sufficient liquidity with efficient users - the surviving banks - is the primary cause for this price drop. Assisting the surviving banks in the purchase of assets by providing them with sufficient liquidity can ensure that the market-clearing price for asset sales never falls enough to draw outsiders into the market. Effectively, the regulator can enable the surviving banks to buy failed banks at lower prices than the outsiders (that is, price discriminate) and thereby eliminate the allocation inefficiency. We show that the minimum amount of liquidity provision required to just keep the outsiders out of the market for asset sales entails the same 
fiscal cost as the ex-post optimal bailout policy.

Next, we compare the two policies - the ex-post optimal bailout policy and its welfareequivalent liquidity provision policy - from an ex-ante standpoint in a setting where banks differentiate or herd taking account of the costs and benefits of doing so. Specifically, we assume that each bank invests either in a common industry or in a bank-specific industry. This decision affects the correlation of bank returns and in turn the likelihood that banks fail together. Ex ante, the regulator wishes to implement a low correlation between banks' investments in order to minimize the likelihood that many banks fail, and simultaneously implement resolution policies that are ex-post optimal.

Employing the bailout policy, the regulator can implement such a welfare-maximizing outcome only if it can commit to sufficiently diluting the share of bank owners when they are bailed out. By so doing, the regulator can make bailout subsidies small enough that banks have incentives to specialize in order to capture the surplus from buying assets at cash-inthe-market prices. However, assumption (iii) implies that such a dilution may not always be feasible. If the moral hazard due to private benefits is sufficiently high, then excessive dilution of a bank's equity leads bank owners to choose bad projects and this generates continuation values that are worse than liquidation values. In this case, the only credible mechanism through which the regulator can implement low correlation is committing to liquidate a sufficiently large number of failed banks. In general, this is ex-post inefficient and thus lacks commitment. We show that this time-inconsistency problem leads to inefficient herding by banks when the likelihood of bank failure is sufficiently high.

Crucially, the liquidity provision policy differs from the bailout policy from an ex-ante standpoint in an interesting fashion. By virtue of assisting surviving banks in acquiring more failed banks, the liquidity provision policy increases the anticipated surplus for banks in states with cash-in-the-market prices. In turn, this strengthens incentives of banks to differentiate from each other. Formally, we show that relative to the ex-post equivalent bailout policy, the liquidity provision policy can implement a low correlation between banks' investments for a wider parameter range, in terms of the severity of the moral hazard problem due to private benefits. To summarize, an important policy implication of our analysis is that a specific form of the lender-of-last-resort (LOLR) policy - one that supports surviving banks rather than the troubled ones - can ameliorate the commitment problem in optimal resolution of bank failures.

In an important extension contained in the unabridged version of the paper, we allow banks to issue equity against their future profits. Equity issuance has a positive effect on prices of failed banks' assets. This improves welfare since assets are purchased by surviving banks over a larger range of bank failures. Also, higher prices increase proceeds from asset sales and this alleviates the fiscal cost for the regulator from providing deposit insurance 
funds. However, the price for shares of surviving banks follows an interesting pattern. When the number of failures is large, cash-in-the-market pricing results in the price of failed banks' assets falling below the threshold value of outsiders. Since purchasing failed banks' assets at such prices becomes profitable for outsiders, in equilibrium they must be compensated for purchasing shares in surviving banks. As a result, share price of surviving banks also falls below their fundamental value. Thus, limited funds within the whole system and the resulting cash-in-the-market pricing affects not only the price of failed banks' assets but also the price of shares of surviving banks.

Our paper is related to the banking literature that has focused on optimal bank closure policies. Mailath and Mester (1994) and Freixas (1999) discuss the time-inconsistency of closure policy in a single-bank model. Penati and Protopapadakis (1988) assume that the regulator provides insurance to uninsured depositors when the number of banking failures is large, and illustrate that this leads banks to invest inefficiently in common markets so as to attract deposits at a lower cost. Mitchell (1997) considers an argument along the lines of the "signal-jamming" model of Rajan (1994) to show that if the regulator bails out banks when they fail together, then banks coordinate on disclosing their losses and delay classifying bad loans by rolling them over. Perotti and Suarez (2002) consider a dynamic model where selling failed banks to surviving banks (reducing competition) increases the charter-value of surviving banks and gives banks ex-ante incentives to stay solvent. However, in contrast to our model, their paper does not examine the effect of closure policies on inter-bank correlation.

Diamond and Rajan (2003) show that a bank failure can cause aggregate liquidity shortages and regulatory intervention may be optimal. The focus of their paper is on demonstrating the liquidity channel of contagion and the difficulty of resolving it ex post, but not on its implications for the ex-ante investment choices of banks.

While direct exposure to common risks is one reason banks may fail together, inter-bank linkages may also lead to joint failures since these linkages may lead to the problems of one bank being transmitted to other banks in a contagion-type phenomenon, as analyzed by Rochet and Tirole (1996), Allen and Gale (2000) and Kahn and Santos (2005).

Finally, some of the ideas presented in this paper are related to the analysis in Acharya (2001) and Acharya and Yorulmazer (2004). In our opinion, the strongest differentiating point of the current paper is its modelling generality in allowing for $n$ banks (rather than a single bank or two banks as in the cited papers) and endogenously deriving the cash-in-the-market pricing as well as the ex-ante and the ex-post optimal bailout policies. This lends the model an element of richness that we have exploited to provide an in-depth normative analysis of various options available to regulators to resolve and restructure failed banks. Acharya and Yorulmazer (2004), which considers a two-bank version of this model, focuses more on the positive analysis: It compares the too-big-to-fail problem with the too-many-to-fail problem 
and shows that herding incentives are stronger for small banks than for large banks, but it does not consider the liquidity provision role of the central bank in assisting purchases of failed banks by surviving banks - a novel policy implication of analysis in this paper.

The remainder of the paper is structured as follows. Section 2 and Section 3 present the model and the analysis. Section 5 considers extensions of the benchmark model. Section 6 concludes. Proofs not contained in the text are contained in the Appendix.

\section{Model}

The benchmark model is outlined in Figure 1. We consider an economy with three dates $t=0,1,2, n$ banks, bank owners, depositors, outside investors, and a regulator. Each bank can borrow from a continuum of depositors of measure 1. Bank owners, as well as depositors, are risk-neutral, and obtain a time-additive utility $u_{t}$ where $u_{t}$ is the expected wealth at time $t$. Depositors receive a unit of endowment at $t=0$ and $t=1$. Depositors also have access to a reservation investment opportunity that gives them a utility of 1 per unit of investment. In each period, that is at date $t=0$ and $t=1$, depositors choose to invest their good in this reservation opportunity or in their bank.

Deposits take the form of a simple debt contract with maturity of one period. In particular, the promised deposit rate is not contingent on investment decisions of the bank or on realized returns. In order to keep the model simple and yet capture the fact that there are limits to equity financing due to associated costs (for example, due to asymmetric information as in Myers and Majluf, 1984), we do not consider any bank financing other than deposits. We relax this assumption partly in an extension in the Appendix.

Banks require one unit of wealth to invest in a risky technology. The risky technology is to be thought of as a portfolio of loans to firms in the corporate sector. The performance of the corporate sector determines its random output at date $t+1$. We assume that all firms in the sector can either repay fully the borrowed bank loans or they default on these loans. In case of a default, we assume for simplicity that there is no repayment.

Suppose $R_{t}$ is the promised return on a bank loan at time $t$. We denote the random repayment on this loan as $\widetilde{R}_{t}, \widetilde{R}_{t} \in\left\{0, R_{t}\right\}$. The probability that the return from these loans is high in period $t$ is $\alpha_{t}$ :

$$
\widetilde{R}_{t}=\left\{\begin{array}{c}
R_{t} \quad \text { with probability } \alpha_{t}, \\
0 \quad \text { with probability } 1-\alpha_{t} .
\end{array}\right.
$$

We assume that the returns in the two periods are independent but allow the probability, as

well as the level of the high return, to be different in the two periods. This helps isolate their effect on our results. 
There is a potential for moral hazard at the level of an individual bank. If the bank chooses a bad project, then when the return is high, it cannot generate $R_{t}$ but only $\left(R_{t}-\bar{\Delta}\right)$ and its owners enjoy a non-pecuniary benefit of $B<\bar{\Delta}$. Therefore, for the bank owners to choose the good project, appropriate incentives have to be provided by giving them a minimum share of the bank's profits. We denote the share of bank owners as $\theta$. If $r_{t}$ is the cost of borrowing deposits, then the incentive-compatibility constraint is:

$$
\alpha_{t}\left[\theta\left(R_{t}-r_{t}\right)\right] \geqslant \alpha_{t}\left[\theta\left(\left(R_{t}-\bar{\Delta}\right)-r_{t}\right)+B\right] . \quad(I C)
$$

We have assumed that the bank is able to pay the promised return of $r_{t}$ when the investment had the high return irrespective of whether the project is good or bad. The left hand side of the $(I C)$ constraint is the expected profit for the bank from the good project when it has a share of $\theta$ of the profit. On the right hand side, we have the expected profit from the bad project when bank owners have a share of $\theta$, plus the non-pecuniary benefit of choosing the bad project. Using this constraint, we can show that bank owners need a minimum share of $\bar{\theta}=\frac{B}{\bar{\Delta}}$ to choose the good project. ${ }^{4}$ We assume that at $t=0$, the entire share of the bank profits belongs to the bank owners, and therefore, there is no moral hazard to start with.

In addition to banks and depositors, there are risk-neutral outside investors who have limited funds amounting to $w$ to purchase banking assets were these assets to be sold. Outsiders do not have the skills to generate the full value from banking assets. In particular, outsiders are inefficient users of banking assets relative to the bank owners, provided bank owners operate good projects. This can be considered a metaphor for some form of expertise or "learning-by-doing" effect for making and administering loans. It is also a simple way of introducing barriers to entry in the banking sector. To capture this formally, we assume that outsiders cannot generate $R_{t}$ in the high state but only $\left(R_{t}-\Delta\right)$. Thus, when the banking assets are sold to outsiders, there may be a social welfare loss due to a misallocation of the assets. We also assume that $\bar{\Delta}>\Delta$ so that outsiders can generate more than what the banks can generate from bad projects.

The notion that outsiders may not be able to use the banking assets as efficiently as the existing bank owners is akin to the notion of asset-specificity, first introduced in the corporatefinance literature by Williamson (1988) and Shleifer and Vishny (1992). In summary, this literature suggests that firms, whose assets tend to be specific, that is, whose assets cannot be readily redeployed by firms outside of the industry, are likely to experience lower liquidation values because they may suffer from "fire-sale" discounts in cash auctions for asset sales, especially when firms within an industry get simultaneously into financial or economic distress. ${ }^{5}$ In the evidence of such specificity for banks and financial institutions, James (1991) shows

\footnotetext{
${ }^{4}$ See Hart and Moore (1994) and Holmstrom and Tirole (1998) for models with similar incentivecompatibility constraints.

${ }^{5}$ There is strong empirical support for this idea in the corporate-finance literature, as shown, for example,
} 
that the liquidation value of a bank is typically lower than its market value as an ongoing concern. In particular, his empirical analysis of the determinants of the losses from bank failures reveals a significant difference in the value of assets that are liquidated and similar assets that are assumed by acquiring banks.

Finally, there is a regulator who employs policy instruments such as bailouts, liquidity provision and sale of failed banks' assets through auctions with the objective of maximizing the total output generated by the banking sector net of any costs associated with these policy options. These policies are assumed to be rationally anticipated by banks and depositors. Below we describe these policies informally. The formal description follows in the model analysis.

We assume that deposits are fully insured in the first period. The provision of immediate funds to pay off failed deposits, net of any proceeds from the sale of failed banks' assets, entails fiscal costs for the regulator (assumed to be exogenous to the model). The fiscal costs of providing funds to the banking sector with immediacy can be linked to a variety of sources, most notably, (i) distortionary effects of tax increases required to fund deposit insurance and bailouts; and, (ii) the likely effect of huge government deficits on the country's exchange rate, manifested in the fact that banking crises and currency crises have often occurred as "twins" in many countries (especially, in emerging market countries). Ultimately, the fiscal cost we have in mind is one of immediacy: Government expenditures and inflows during the regular course of events are smooth, relative to the potentially rapid growth of "off-balancesheet contingent liabilities" such as deposit-insurance funds, costs of bank bailouts, costs of liquidity provision etc. ${ }^{6}$

Note that the second period is the last period in our model and there is no further investment opportunity. As a result, our analysis is not affected by whether deposits are insured for the second investment or not.

If the bank return from the first-period investment is high, then the bank operates one more period and makes the second-period investment. If the return is low, then the bank is in default. We assume that the surviving banks (if any) use their first-period profits (and the liquidity provided by the regulator, if any) to purchase failed banks' assets. The regulator

by Pulvino (1998) for the airline industry, and by Acharya, Bharath, and Srinivasan (2003) for the entire universe of defaulted firms in the US over the period 1981 to 1999 (see also Berger, Ofek, and Swary (1996) and Stromberg (2000)).

${ }^{6}$ See, for example, the discussion on fiscal costs associated with banking crises in Calomiris (1998). Hoggarth, Reis and Saporta (2001) find that the cumulative output losses have amounted to a whopping 15-20\% annual GDP in the banking crises of the past 25 years. Caprio and Klingebiel (1996) argue that the bailout of the thrift industry cost $\$ 180$ billion (3.2\% of GDP) in the US in the late 1980s. They also document that the estimated cost of bailouts were $16.8 \%$ for Spain, $6.4 \%$ for Sweden and $8 \%$ for Finland. Honohan and Klingebiel (2000) find that countries spent $12.8 \%$ of their GDP to clean up their banking systems whereas Claessens, Djankov and Klingebiel (1999) set the cost at 15-50\% of GDP. 
decides whether to bail out some or all of the failed banks or to let the surviving banks (if any) and/or outsiders purchase failed banks' assets, and whether to assist the surviving banks in purchasing assets by providing them liquidity at zero cost. In particular, the regulator simply transfers liquidity without it being returned back by the banks in the future. ${ }^{7}$ Note that given the relative expertise of banks compared to outsiders, it is never optimal provide liquidity to outsiders. When a bank is bailed out, the regulator may dilute the equity share of bank owners. Proceeds from the sale of failed banks reduce the costs of providing deposit insurance. Hence, bailouts are associated with an opportunity cost for the regulator. Similarly, provision of liquidity (if subsidized) also increases the costs of providing deposit insurance. These costs are also a part of the regulator's objective function.

Depending on the first period returns, some of the banks (say $k$ out of $n$ ) fail. Since banks are identical at $t=0$, we denote the possible states at $t=1$ with $k$, the number of bank failures.

\section{Analysis}

We analyze the model proceeding backwards from the second period to the first period.

The promised deposit rate at $t=0,1$ is denoted by $r_{t}$. We assume throughout that $R_{t}>r_{t}$ for $t=0,1$.

The surviving banks operate for another period at $t=1$. Since, the returns from each period's investments are assumed to be independent, the probability of having the high return for each bank is equal to $\alpha_{1}$. As this is the last period there is no further investment opportunity. The expected payoff to the bank from its second-period investment, $E\left(\pi_{2}\right)$, is thus

$$
E\left(\pi_{2}\right)=\alpha_{1}\left[R_{1}-r_{1}\right]
$$

Note that this payoff is independent of inter-bank correlation.

For a bank to continue operating for another period, it needs to pay its old depositors $r_{0}$ and it needs an additional one unit of wealth for the second investment. A failed bank cannot generate the needed funds, $\left(1+r_{0}\right)$, from its depositors at $t=1$ : Its depositors are endowed with only one unit of wealth at $t=1$. Thus, the bank is in default. An important possibility is that the surviving banks and/or outsiders may purchase the assets of failed banks. Next, we investigate sales of failed banks' assets and the resulting asset prices.

\footnotetext{
${ }^{7}$ Note that this policy is basically a sale of failed banks' assets with government assistance, similar to a purchase and assumption aggrement. See the discussion in Section 5.1.
} 


\subsection{Asset sales and liquidation values}

In examining the purchase of failed banks' assets, several interesting issues arise. First, surviving banks and outsiders may compete with each other if there are enough resources with them to acquire all failed banks' assets. Second, unless the game for asset acquisition is specified with reasonable restrictions, an abundance of equilibria arises. Third, surviving banks in fact may not have enough resources to acquire all failed banks. Hence, the regulator may find it optimal to intervene to sell as many failed banks' assets as possible to surviving banks, bail out some others and/or provide liquidity to surviving banks to be used in the asset purchase. To start with, we examine asset sales and prices without bailouts and liquidity provision.

To keep the analysis tractable and, at the same time, reasonable, we make the following assumptions:

(i) The regulator pools all failed banks' assets and auctions these assets to the surviving banks and the outsiders. Assets of a failed bank can be acquired partially, and when a portion of these assets are acquired, the purchasing bank can also access the same portion ("branches") of the failed bank's depositors. In essence, the bank can be sold in parts. This assumption of partial bank sales is motivated by the literature on share auctions (Wilson, 1979) and simplifies the analysis substantially. When only a part of the total failed banks' assets are sold and the remaining are bailed out, the assets to be sold are chosen randomly.

(ii) Denoting the surviving banks as $i \in\{1,2, \ldots,(n-k)\}$ and the outsiders as $i=0$, each surviving bank and outsiders submit a schedule $y_{i}(p)$ for the amount of assets they are willing to purchase as a function of the price $p$ at which a unit of the banking asset (inclusive of associated deposits) is being auctioned, where $y_{i}(p) \in[0, k]$.

(iii) We assume that surviving banks cannot raise additional financing from the markets, an assumption we relax in an extension in the Appendix. Hence, the resources available with each surviving bank for purchasing failed banks' assets, denoted by $l$, equal the first-period profits, that is, $l=\left(R_{0}-r_{0}\right)$. In Section 3.3, we allow the regulator to provide surviving banks some liquidity to be used for the asset purchase.

(iv) The regulator cannot price-discriminate in the auction. Later on, in Section 3.3, we relax this assumption and let the regulator provide liquidity to surviving banks to be used for asset purchase, which can be shown to be equivalent to some sort of price discrimination.

(v) The regulator determines the auction price $p$ so as to maximize the expected output of the banking sector, subject to the natural constraint that portions allocated to surviving banks and outsiders add up at most to the number of failed banks, that is, $\sum_{i=0}^{n-k} y_{i}(p) \leq k$. Given the allocation inefficiency of selling assets to outsiders, it turns out that if the surviving banks and the outsiders pay the same price for the failed banks' assets, the regulator allocates 
the maximum amount he can to the surviving banks.

(vi) We focus on the symmetric outcome where all surviving banks submit the same schedule, that is, $y_{i}(p)=y(p)$ for all $i \in\{1,2, \ldots,(n-k)\}$.

First, we derive the demand schedule for surviving banks. Let $\bar{p}=\left[\alpha_{1}\left(R_{1}-r_{1}\right)\right]=E\left(\pi_{2}\right)$, which is the expected profit for a surviving bank from the risky asset in the second period. Note that the expected profit of a surviving bank from the asset purchase can be calculated as:

$$
y(p)[\bar{p}-p] .
$$

The surviving bank wishes to maximize these profits subject to the resource constraint

$$
y(p) \cdot p \leq l .
$$

Hence, for $p<\bar{p}$, surviving banks are willing to purchase the maximum amount of failed banks' assets using their resources. Thus, for $p<\bar{p}$, optimal demand schedule for surviving banks is

$$
y(p)=\frac{l}{p} .
$$

For $p>\bar{p}$, the demand is $y(p)=0$, and for $p=\bar{p}, y(p)$ is indeterminate. In words, as long as purchasing bank assets is profitable, a surviving bank wishes to use up all its resources to purchase failed banks' assets. For a formal proof of this result that takes into account the correlation structure of assets, see the Appendix.

We can derive the demand schedule for outsiders in a similar way. Note that, outsiders can generate only $\left(R_{1}-\Delta\right)$ in the high state. Let $\underline{p}=\left[\alpha_{1}\left(\left(R_{1}-\Delta\right)-r_{1}\right)\right]=\left[\bar{p}-\alpha_{1} \Delta\right]$, the expected profit for the outsiders from the risky asset in the second period.

For $p<\underline{p}$, outsiders are willing to supply all their funds for the asset purchase. Thus, for $p<\underline{p}$, outsiders' optimal demand schedule is

$$
y_{0}(p)=\frac{w}{p} .
$$

For $p>\underline{p}$, the demand is $y_{0}(p)=0$, and for $p=\underline{p}, y_{0}(p)$ is indeterminate. Thus, for $p>\underline{p}$, there is limited participation in the market for banking assets.

Next, we analyze how the regulator optimally allocates the failed banks' assets and the price function that results.

We know that in the absence of financial constraints, the efficient outcome is to sell the failed banks' assets to surviving banks. However, the surviving banks may not be able to pay 
the threshold price of $p$ for all failed banks' assets. If prices fall further, these assets become profitable for the outsiders and they participate in the auction.

The regulator cannot set $p>\bar{p}$ since in this case we have $y(p)=y_{0}(p)=0$. If $p \leqslant \bar{p}$, and the number of failed banks is sufficiently small, the surviving banks have enough funds to pay the full price for all the failed banks' assets. More specifically, for $k \leq \underline{k}$, where

$$
\underline{k}=\text { floor }\left(\frac{n l}{l+\bar{p}}\right)
$$

and floor $(z)$ is the largest integer smaller than or equal to $z$, the regulator sets the auction price at $p^{*}=\bar{p}$. At this price, surviving banks are indifferent between any quantity of assets purchased. Hence, the regulator can allocate a share $y\left(p^{*}\right)=\frac{k}{(n-k)}$ to each surviving bank.

For moderate values of $k$, surviving banks cannot pay the full price for all failed banks' assets but can still pay at least the threshold value of $p$, below which outsiders have a positive demand. Formally, for $k \in\{\underline{k}+1, \ldots, \bar{k}\}$, where

$$
\bar{k}=\text { floor }\left(\frac{n l}{l+\underline{p}}\right)
$$

the regulator sets the price at $p^{*}=\left(\frac{(n-k) l}{k}\right)$, and again, all banking assets are acquired by the surviving banks. Note that, in this region, surviving banks use all available funds and the price falls as the number of failures increases. This effect is basically the cash-in-themarket pricing as in Allen and Gale $(1994,1998)$ and is also akin to the industry-equilibrium hypothesis of Shleifer and Vishny (1992) who argue that when industry peers of a firm in distress are financially constrained, the peers may not be able to pay a price for assets of the distressed firm that equals the value of these assets to them.

For $k>\bar{k}$, the surviving banks cannot pay the threshold price of $\underline{p}$ for all failed banks' assets and profitable options emerge for outsiders. At this point, outsiders have a positive demand and are willing to supply their funds for the asset purchase. With the injection of outsider funds, prices can be sustained at $\underline{p}$ until some critical number of failures $\overline{\bar{k}} \geqslant \bar{k}$. However, for $k>\overline{\bar{k}}$, even the injection of outsiders' funds is not enough to sustain the price at $\underline{p}$.

Formally, for $k \in\{\bar{k}+1, \ldots, \overline{\bar{k}}\}$, where

$$
\overline{\bar{k}}=\text { floor }\left(\frac{n l+w}{l+\underline{p}}\right),
$$

the regulator sets the price at $\underline{p}$. At this price, outsiders are indifferent between any quantity of assets purchased. Hence, the regulator can allocate a share of $y(\underline{p})=\left(\frac{l}{\underline{p}}\right)$ to each surviving bank and the rest, $y_{0}(\underline{p})=\left(k-\frac{(n-k) l}{\underline{p}}\right)$, to outsiders. 
And beyond this point, that is, $k>\overline{\bar{k}}$, the price is again strictly decreasing in $k$ and is given by

$$
p^{*}(k)=\frac{(n-k) l+w}{k},
$$

and $y\left(p^{*}\right)=\left(\frac{l}{p^{*}}\right)$ and $y_{0}\left(p^{*}\right)=\left(\frac{w}{p^{*}}\right)$.

The resulting price function is downward-sloping in the number of failed banks $k$ in two separate regions. In the first downward-sloping region, outsiders have not yet entered the market $(k \in\{\underline{k}+1, \ldots, \bar{k}\})$ and there is cash-in-the-market pricing given the limited liquidity of surviving banks. In the second downward-sloping region, even the liquidity of outsiders is not enough to sustain the price at $p$, their highest valuation of banking assets. Thus, there is cash-in-the-market pricing in this region given the limited liquidity of the entire set of market players bidding for failed assets, that is, of surviving banks as well as outsiders. This price function is formally stated in the following proposition and is illustrated in Figure 2.

Proposition 1 In the absence of bailout and liquidity provision policies, the price of failed banks' assets as a function of the number of failed banks is as follows:

$$
p^{*}(k)=\left\{\begin{array}{ccc}
\bar{p} & \text { for } & k \leqslant \underline{k} \\
\frac{(n-k) l}{k} & \text { for } & k \in\{\underline{k}+1, \ldots, \bar{k}\} \\
\underline{p} & \text { for } & k \in\{\bar{k}+1, \ldots, \overline{\bar{k}}\} \\
\frac{[(n-k) l]+w}{k} & \text { for } & k>\overline{\bar{k}}
\end{array} .\right.
$$

Note that by assumption (iii), surviving banks cannot raise additional financing from the markets. In an extension in the Appendix, we relax this assumption and show that our results are robust to allowing surviving banks to issue equity. In this case, we have two markets: one for assets of failed banks and one for shares of surviving banks. When the number of failures is large, that is, when $k>\overline{\bar{k}}$, cash-in-the-market pricing results in the price of failed banks' assets falling below the threshold value of outsiders, $p$. Since purchasing failed banks' assets at such prices becomes profitable for outsiders, in equilibrium they must be compensated for purchasing shares in surviving banks. As a result, share price of surviving banks also falls below their fundamental value, $\bar{p}$ (see Figures 8 and 9). In other words, surviving banks can raise equity financing only at discounts. The resulting dilution limits their ability to raise such financing and purchase more of failed banks' assets. Thus, limited funds within the whole system and the resulting cash-in-the-market pricing affects not only the price of failed banks' assets but also the price of shares of surviving banks. Hence, for simplicity, in the rest of the paper, we focus on the case where banks cannot generate funds against their future returns. 


\subsection{Bailouts}

To summarize the result from the previous analysis, when the number of bank failures is sufficiently small, $k \leq \bar{k}$, all failed banks' assets are resolved through a purchase by surviving banks. Since this allocation entails no welfare losses, the regulator does not have any incentive to intervene ex post. In contrast, if $k>\bar{k}$, then some of these assets are purchased by outsiders who are not the most efficient users. Hence, the regulator compares the misallocation cost resulting from asset sales to outsiders with the cost of bailing out failed banks. Since the misallocation cost is constant at $\left(\alpha_{1} \Delta\right)$ per unit of failed banks' assets, the regulator bails out failed banks as long as the marginal cost of a bailout is less than this misallocation cost.

Note that for a failed bank to continue operating, it needs a total of $\left(r_{0}+1\right)$ units. Since available deposits for a bank amount to only one unit (the $t=1$ endowment of its depositors), the bank cannot operate unless the regulator injects $r_{0}$ at $t=1$. Under our assumption of full deposit insurance, the regulator does inject $r_{0}$ at $t=1$, so that a bailout is equivalent to the regulator granting permission to a failed bank's owners to operate one more period.

In order to analyze the regulator's decision to bail out or liquidate failed banks, we make the following assumptions:

(i) The regulator incurs a fiscal cost of $f(c)$ when it injects $c$ units of funds into the banking sector. We assume this cost function is strictly increasing and convex (possibly linear): $f^{\prime}>0$ and $f^{\prime \prime} \geq 0$. We do not model this cost for which we have in mind fiscal and opportunity costs to the regulator from providing funds with immediacy to the banking sector (see footnote 6).

(ii) If the regulator decides not to bail out a failed bank, the existing depositors are paid back $r_{0}$ through deposit insurance and the failed bank's assets are sold at the market-clearing price. Thus, when the regulator bails out $b$ of the $k$ failed banks, the fiscal cost incurred is $f\left(k r_{0}-(k-b) \cdot p^{*}(k-b)\right)$ as proceeds from sale of the remaining $(k-b)$ banks are $\left[(k-b) \cdot p^{*}(k-b)\right]$.

The crucial difference between bailouts and asset sales from an ex-post standpoint is that proceeds from asset sales lower the fiscal cost from immediate provision of deposit insurance, whereas bailouts produce no such proceeds. In other words, bailouts entail an opportunity cost to the regulator in fiscal terms.

(iii) The regulator can take an equity share in the bailed out bank(s). Let $\beta$ be the share the regulator takes in a bailed out bank. If the bailed out bank has a high return from the second investment (which has a probability of $\alpha_{1}$ ), then the regulator gets back $\beta\left(R_{1}-r_{1}\right)$ at $t=2$. Ex post, such dilution of a bailed-out bank's equity is merely a transfer from the bank owners to the regulator. However, as argued before, if the regulator takes a share greater than $(1-\bar{\theta})$, then the bank owners are left with a share of less than $\bar{\theta}$, the critical share below which the bank chooses the bad project. Since sales to outsiders generate a higher payoff 
compared to that from a bailed-out bank that chooses a bad project $(\bar{\Delta}>\Delta)$, the regulator never takes a share greater than $(1-\bar{\theta})$. As the value of this stake will be realized in the future, it is assumed not to affect the cost of providing deposit insurance with immediacy.

We characterize the optimal bailout policy under these assumptions. The regulator's objective is to maximize the total expected output of the banking sector net of any bailout or liquidation costs. As argued before, the regulator never intervenes when $k \leqslant \bar{k}$.

When $k \in\{\bar{k}+1, \ldots, \overline{\bar{k}}\}$, the price for failed banks' assets is $\underline{p}$ and the marginal cost of bailing out the $b^{\text {th }}$ bank is

$$
g(k, b)=f\left(k r_{0}-(k-b) \underline{p}\right)-f\left(k r_{0}-(k-b+1) \underline{p}\right) .
$$

This marginal cost is (at least weakly) increasing in $b .{ }^{8}$ Hence, there is a maximum number of banks, denoted by $\bar{b}(k)$, up to which the bailout costs are smaller than misallocation costs. Formally, $\bar{b}(k)$ satisfies the following conditions:

$$
g(k, \bar{b}) \leqslant \alpha_{1} \Delta<g(k, \bar{b}+1)
$$

The maximum number of banks that can be acquired by the surviving banks is $(n-k) y(\underline{p})$, where $y(\underline{p})=\frac{l}{p}$. Thus, the regulator bails out $b^{*}(k)=\min \{\bar{b}(k),[k-(n-k) y(\underline{p})]\}$ banks.

Finally, when $k>\overline{\bar{k}}$, all the funds of the surviving banks and the outsiders, a total of $[(n-k) l+w]$, are collected through the sale of the failed banks' assets. Hence, if the regulator decides to bail out a bank, the proceeds from the asset sale are not affected and bailouts do not incur any (opportunity) fiscal cost. Thus, the regulator first bails out $\widehat{b}(k)$ failed banks where $\widehat{b}(k)$ is the maximum number of bailouts such that the regulator can collect all the available liquidity in the system, $[(n-k) l+w]$, by selling the remaining $[k-\widehat{b}(k)]$ banks. Note that when the regulator bails out $\widehat{b}(k)$ failed banks, the price for the remaining $[k-\widehat{b}(k)]$ failed banks' assets reaches $\underline{p}$. Formally, we have

$$
(n-k) l+w=(k-\widehat{b}(k)) \underline{p},
$$

which gives us

$$
\widehat{b}(k)=\left[k-\frac{(n-k) l+w}{\underline{p}}\right] .
$$

\footnotetext{
${ }^{8}$ In particular, $\frac{\partial g}{\partial b}=\underline{p}\left[f^{\prime}\left(k r_{0}-(k-b) \underline{p}\right)-f^{\prime}\left(k r_{0}-(k-b+1) \underline{p}\right)\right]$.
}

Note that, $\left(k r_{0}-(k-b) \underline{p}\right)>\left(k r_{0}-(k-b+1) \underline{p}\right)$, and since $f^{\prime \prime} \geq 0$, we have $\frac{\partial g}{\partial b} \geq 0$. 
From this point on, the outsider funds are sufficient to sustain the price for asset sales of remaining $[k-\widehat{b}(k)]$ banks at the level $\underline{p}$ and an additional bailout decreases the proceeds from asset sales by $\underline{p}$. Hence, the regulator's decision to bail out additional banks is similar to that for the case where $k \in\{\bar{k}+1, \ldots, \overline{\bar{k}}\}$. In particular, the regulator bails out a total of $\widehat{b}(k)+\overline{\bar{b}}(k)]$ banks, until the marginal bailout cost starts exceeding the misallocation cost. Thus, $\overline{\bar{b}}(k)$ is given by the condition:

$$
h(k, \overline{\bar{b}}) \leqslant \alpha_{1} \Delta<h(k, \overline{\bar{b}}+1)
$$

where $h(k, b)$ is defined as:

$$
h(k, b)=f\left(k r_{0}-((k-\widehat{b}(k))-\overline{\bar{b}}) \underline{p}\right)-f\left(k r_{0}-((k-\widehat{b}(k))-\overline{\bar{b}}+1) \underline{p}\right) .
$$

Note that the marginal bailout cost $h(k, b)$ reflects the fact that with $[\widehat{b}(k)+\overline{\bar{b}}]$ bailouts, the regulator receives proceeds from asset sales amounting to $[(k-\widehat{b}(k))-\overline{\bar{b}}) \underline{p}]$.

To summarize, the regulator's optimal bailout policy $b^{*}(k)$ is such that

$$
b^{*}(k)=\left\{\begin{array}{ccc}
\min \{\bar{b}(k),[k-(n-k) y(\underline{p})]\} & \text { for } & k \in\{\bar{k}+1, \ldots, \overline{\bar{k}}\} \\
\min \{\widehat{b}(k)+\overline{\bar{b}}(k),[k-(n-k) y(\underline{p})]\} & \text { for } & k>\overline{\bar{k}}
\end{array} .\right.
$$

Banks are chosen randomly between the three options of being sold to surviving banks, bailed out, or liquidated to outsiders, and the regulator takes a share of $\beta$ in all bailed-out banks.

We state this closure/bailout policy formally in a proposition:

Proposition 2 Under the ex-post optimal bailout policy,

(i) When $k \leqslant \bar{k}$, surviving banks purchase all failed banks' assets and the regulator does not intervene.

(ii) When $k>\bar{k}$, the regulator bails out $b^{*}(k)$ of the $k$ failed banks, where $b^{*}(k)$ is defined by conditions (14), (17) and (19). The banks to be bailed out are chosen randomly with equal probability.

The optimal bailout policy has the intuitive property that in states with a large number of bank failures, there are "too many (banks) to liquidate" and the regulator is forced to bail out some of the failed banks. In particular, irrespective of the fiscal cost function, it is always optimal to bail out up to $\widehat{b}(k)$ banks in the region of high bank failures, $k>\overline{\bar{k}}$, or, in other words, in the region of cash-in-the-market pricing due to limited liquidity of the 
entire market for banking assets. Bailouts in this region entail no opportunity costs for the regulator but help avoid misallocation costs. ${ }^{9}$

With bailouts, the price never falls below the reservation price of outsiders, $p$. The resulting price function is illustrated in Figure 3. It differs from Figure 2, the no bail-out case, along an important dimension, that is, there is only one downward-sloping region in Figure 3 compared to Figure 2.

Note that the bailout policy $b^{*}(k)$ is not always monotone increasing in $k$ over the entire range. This is because the marginal cost of bailout, $g(k, b)$, is strictly increasing in $k$ if the fiscal cost function is strictly convex: with more bank failures, the fiscal cost of deposit insurance is higher, and given the convexity of this cost function, incurring the opportunity cost of bailouts becomes more severe. In other words, $\bar{b}(k)$ is decreasing in $k$ when the cost function is convex. A similar argument applies to the marginal cost $h(k, b)$ and the $\overline{\bar{b}}(k)$. The general behavior of the bailout policy $b^{*}(k)$ is illustrated in Figure 4. Nevertheless, note that $b^{*}(k)$ has the property that bailouts occur only when bank failures are sufficiently large in number $(k>\bar{k})$, and, if large enough to reach the second cash-in-the-market price region $(k>\bar{k})$, then the opportunity cost of bailouts becomes zero (up to bailouts of $\widehat{b}(k)$ banks).

In order to derive and exploit a closed-form expression for the optimal bailout policy, it is useful to consider a linear cost function: $f(c)=F c, F>0$. One analytical advantage of the linear cost function is that the bailout policy $b^{*}(k)$ is now always monotone increasing. Specifically, we obtain that $b^{*}(k)=\left[k-\frac{(n-k) l}{\underline{p}}\right]$, for $k>\bar{k}$, if the cost parameter $F$ is sufficiently small, and $b^{*}(k)=\widehat{b}(k)$, for only $k>\overline{\bar{k}}$, otherwise. In words, when the fiscal cost parameter is small, outsiders are kept entirely out of the market for banks sales: surviving banks acquire as many failed banks as they can and the remaining (if any) failed banks are bailed out. When the fiscal cost parameter is large, outsiders participate in asset sales until the number of bank failures is high enough that the second cash-in-the-market region is reached. At this point, all incremental banks that have failed are bailed out. The resulting bailout policy is given by the following corollary and is illustrated in Figure 5 .

Corollary 1 With a linear fiscal cost function $f(c)=F c$, the regulator bails out $b^{*}(k)$ of the $k$ failed banks when $k>\bar{k}$, where $b^{*}(k)$ is defined as follows:

(i) When $F \leq \frac{\alpha_{1} \Delta}{\underline{p}}$,

$$
b^{*}(k)=\left[k-\frac{(n-k) l}{\underline{p}}\right] .
$$

\footnotetext{
${ }^{9}$ In our model, the level of asset prices have no "mark-to-market" effect on collateral values and future liquidity of surviving banks. In a richer setting with such a collateral channel for the amplification of fire-sale prices, bailouts would be optimal ex post not just to avoid the allocation inefficiency but also to prevent precipitous declines in the market prices of banking assets.
} 
(ii) When $F>\frac{\alpha_{1} \Delta}{\underline{p}}$,

$$
b^{*}(k)=\left\{\begin{array}{ccc}
0 & \text { for } & k \in\{\bar{k}+1, \ldots, \overline{\bar{k}}\} \\
\widehat{b}(k) & \text { for } & k>\overline{\bar{k}}
\end{array} .\right.
$$

where $\widehat{b}(k)$ is given by equation (16).

Note that with the linear fiscal cost function the number of bailed-out banks increases linearly with a slope of $\left(1+\frac{l}{\underline{p}}\right)$ in the number of failed banks $k$. Hence, for an additional bank failure, the number of bailed-out banks increases by more than one. The reason for this is that as more banks fail, not only the failed banks' assets to be sold increase but also the available funds within the surviving banks decrease. As a result, an additional bank failure increases the number of failed banks' assets that cannot be acquired by surviving banks by $\left(1+\frac{l}{p}\right)$. By implication, as more banks fail, the probability of being bailed out $\left(\frac{b^{*}(k)}{k}\right)$ increases, as well. ${ }^{10}$ In other words, as more banks fail, not only the number of bailed-out banks but also the likelihood of being bailed-out for failed banks increase. We interpret this result as a stronger form of the too-many-to-fail problem.

\subsection{Liquidity provision}

As argued, the main reason for bailouts is to prevent allocation inefficiency resulting from sales to outsiders. However, the regulator can employ alternative policies to prevent misallocation of banking assets. We consider a policy of assisting the surviving banks wherein the regulator provides liquidity to these banks without it being returned back in the future to the regulator. Since surviving banks are efficient users of failed banks' assets, this policy of providing subsidized liquidity to surviving banks so that they have enough funds to acquire failed banks' assets can also prevent misallocation of banking assets. Next, we compare the liquidity provision policy and the ex-post optimal bailout policy characterized in Proposition 2 in terms of the level of social welfare from an ex-post standpoint. In particular, we show that a specific form of liquidity provision policy and the ex-post optimal bailout policy result in the same level of ex-post social welfare.

There are two cases to consider: first, when $k \in\{\bar{k}+1, \ldots, \overline{\bar{k}}\}$, and second when $k>\overline{\bar{k}}$.

Note that for $k \in\{\bar{k}+1, \ldots, \overline{\bar{k}}\}$, the injection of outsider funds of $w$ ensures that the price stays at $\underline{p}$ (see Figure 2 ). Thus, bailing out a bank adds $\underline{p}$ to the total funds needed by the regulator to resolve bank failures. Alternatively, if the regulator employs a liquidity provision

\footnotetext{
${ }^{10}$ We have $\frac{\partial\left(b^{*}(k) / k\right)}{\partial k}=\frac{l}{\underline{p}}>0$.
} 
policy, he can provide $p$ units of funds to surviving banks so that surviving banks can acquire the failed banks. Since banks are efficient users of these assets, liquidity provision prevents misallocation of banking assets. Hence, both liquidity provision and bailout policies increase the funds needed by the regulator by $\underline{p}$ and both policies prevent the misallocation cost of $\left(\alpha_{1} \Delta\right)$. Thus, from an ex-post point of view, for $k \in\{\bar{k}+1, \ldots, \overline{\bar{k}}\}$, bailouts and liquidity provision to surviving banks result in the same level of social welfare.

Formally, when the regulator employs the ex-post optimal bailout policy characterized in Proposition 2, for $k \in\{\bar{k}+1, \ldots, \overline{\bar{k}}\}$, the regulator bails out $b^{*}(k)$ banks, where $b^{*}(k)$ is given in equation (14). The proceeds from the asset sales equal $\left(\left(k-b^{*}(k)\right) \underline{p}\right)$. And outsiders acquire $\left(k-\frac{(n-k) l}{\underline{p}}-b^{*}(k)\right)$ units of failed banks' assets. Hence, we can write the social welfare cost as:

$$
C_{b}(k)=f\left(k r_{0}-\left[\left(k-b^{*}(k)\right) \underline{p}\right]\right)+\left[k-\frac{(n-k) l}{\underline{p}}-b^{*}(k)\right]\left(\alpha_{1} \Delta\right) .
$$

The regulator can achieve the same level of ex-post social welfare using the following liquidity provision policy. Suppose the regulator provides $\left(b^{*}(k) \underline{p}\right)$ units of liquidity to surviving banks so that surviving banks can altogether acquire $\left(\frac{(n-k) l}{\underline{p}}+b^{*}(k)\right)$ units of failed banks' assets. Then, under the liquidity provision policy, each surviving bank receives

$$
\widehat{l}(k)=\frac{\left[b^{*}(k)\right] \underline{p}}{(n-k)}
$$

units of liquidity. In this case, all failed banks' assets are sold at a price of $\underline{p}$, resulting in total proceeds of $k \underline{p}$. Outsiders acquire $\left(k-\frac{(n-k) l}{\underline{p}}-b^{*}(k)\right)$ units of failed banks' assets and we can write the social welfare cost as:

$$
C_{l}(k)=f\left(\left[k r_{0}+\left[b^{*}(k)\right] \underline{p}\right]-k \underline{p}\right)+\left[k-\frac{(n-k) l}{\underline{p}}-b^{*}(k)\right]\left(\alpha_{1} \Delta\right)=C_{b}(k) .
$$

Thus, for $k \in\{\bar{k}+1, \ldots, \overline{\bar{k}}\}$, ex-post optimal bailout policy and the liquidity provision policy characterized in equation (23) result in the same level of ex-post social welfare.

For the second case, recall from the discussion of bailouts that for $k>\overline{\bar{k}}$, bailing out up to $\widehat{b}(k)$ banks, where $\widehat{b}(k)$ is given in equation (16), does not incur any (opportunity) fiscal cost. Thus, when $k>\overline{\bar{k}}$, the regulator first bails out $\widehat{b}(k)$ failed banks. At this point, the price for the remaining $[k-\widehat{b}(k)]$ failed banks' assets reaches $\underline{p}$ and an additional bailout decreases the proceeds from the asset sales by $\underline{p}$.

We show that for $k>\overline{\bar{k}}$, just like the bailout policy, a specific form of liquidity provision does not incur any (opportunity) fiscal cost. Under the liquidity provision policy, the regulator 
can provide $(\widehat{b}(k) \underline{p})$ units of liquidity to surviving banks. With these additional funds, surviving banks have a total liquidity of $((n-k) l+\widehat{b}(k) \underline{p})$ units, and with the outsider funds of $w$, this is just enough to keep the price for all failed banks' assets at $\underline{p}$. Now, surviving banks can acquire the $\widehat{b}(k)$ failed banks that were bailed out under the bailout policy. The regulator collects back $(k p)$ units from the sale of failed banks' assets. Thus, the funds needed by the regulator equal $\left[\left(k r_{0}+\widehat{b}(k) \underline{p}\right)-k \underline{p}\right]$, which is identical to the funds needed under the bailout policy.

Once $\widehat{b}(k)$ banks have been sold, the total amount of liquidity in the whole system is sufficient to sustain the price for the sale of remaining $[k-\widehat{b}(k)]$ banks at the level $\underline{p}$, whereby an additional bailout or liquidity provision decreases the proceeds from asset sales by $\underline{p}$. Hence the regulator's decision is similar to that for the case where $k \in\{\bar{k}+1, \ldots, \overline{\bar{k}}\}$. Therefore, as argued above, we can show that the liquidity provision policy and the ex-post optimal bailout policy result in the same level of ex-post social welfare.

Formally, consider a liquidity provision policy of transfering $\widehat{l}(k)$ units of liquidity to each surviving bank for assitance in the asset purchase, where

$$
\widehat{l}(k)=\left\{\begin{array}{clc}
0 & \text { for } & k \leqslant \bar{k} \\
\frac{\left[b^{*}(k)\right] \underline{p}}{(n-k)} & \text { for } & k \in\{\bar{k}+1, \ldots, n-1\} \\
0 & \text { for } & k=n
\end{array}\right.
$$

and, where $b^{*}(k)$ is the ex-post optimal bailout policy characterized in equation (19). This policy achieves the same level of social welfare as the ex-post optimal bailout policy.

Note that, under the liquidity provision policy, for $k>\bar{k}$, surviving banks acquire $\left(\frac{(n-k) l}{\underline{p}}+b^{*}(k)\right)$ units of failed banks' assets using their funds of $((n-k) l)$. Hence, they pay an "effective" price of $p_{e}^{*}(k)$ for each unit of asset they acquire, where

$$
p_{e}^{*}(k)=\left\{\begin{array}{ccc}
\bar{p} & \text { for } & k \leqslant \underline{k} \\
\frac{(n-k) l}{k} & \text { for } & k \in\{\underline{k}+1, \ldots, \bar{k}\} \\
\frac{[(n-k) l] \underline{p}}{\left[(n-k) l+\left(b^{*}(k)\right) \underline{p}\right]} & \text { for } & k \in\{\bar{k}+1, \ldots, n-1\} \\
\underline{p} & \text { for } & k=n .
\end{array} .\right.
$$

Thus, the liquidity provision policy characterized in equation (25) can also be replicated by a policy of price discrimination where the regulator charges the price $p_{e}^{*}(k)$ given in equation (26) to surviving banks and a price $\underline{p}$ for outsiders.

This gives us the following formal Proposition. 
Proposition 3 Ex-post optimal bailout policy given in Proposition 2, the liquidity provision policy characterized in equation (25) and the price-discrimination policy characterized in equation (26) all result in the same level of ex-post social welfare.

\section{Policy analysis}

We already showed that the ex-post optimal bailout policy and the liquidity provision policy result in the same level of social welfare ex post. Hence, from an ex-post point of view, the regulator is indifferent between these policies. In this section, we analyze the ex-ante optimality of these policies. In particular, we allow banks to choose the level of correlation in their investments, analyze the incentives different regulatory policies create for the choice of inter-bank correlation, and compare the resulting social welfare from an ex-ante point of view.

For the remainder of the paper, we use the linear fiscal cost function $f(c)=F c$.

\subsection{Correlation of bank returns}

In this section, we allow banks to choose the level of correlation in their investments. At $t=0$, banks borrow deposits and then choose the composition of loans in their respective portfolios. This choice determines the level of correlation between the returns from their respective investments. We refer to this correlation as "inter-bank correlation".

We suppose that there is a common industry that all banks can access and there are $n$ other industries, one for each bank, such that only bank $i$ can access industry $i$ (region, set of customers, etc.). To focus on the effect of inter-bank correlation, we assume that the returns from the common and the $n$ specific industries have the same return structure and they are independent. That is, the return from industry $i$, denoted by $\widetilde{R}_{i t}$, is given as:

$$
\widetilde{R}_{i t}=\left\{\begin{array}{cll}
R_{i t} & \text { with probability } & \alpha_{t} \\
0 & \text { with probability } & 1-\alpha_{t}
\end{array}\right.
$$

where $i \in\{1,2, \ldots, n\}$ denotes bank-specific industries and $i=c$ denotes the common industry. Banks choose whether to invest a unit of wealth in the bank-specific industry or in the common industry, that is, $x_{i} \in\{0,1\} .{ }^{11}$ The vector of choices $\left(x_{1}, \ldots, x_{n}\right)$ determines the joint probability distribution of bank returns.

\footnotetext{
${ }^{11}$ The case where banks invest both in the common asset as well as in the bank-specific asset gives rise to qualitatively similar results, but is technically quite involved. The two-bank version of this more realistic modelling of bank investments is contained in the Addendum to Acharya and Yorulmazer (2004).
} 
If banks in equilibrium choose to lend to firms in the common industry, then they are assumed to be perfectly correlated, that is, the correlation of banks' returns is $\rho=1$. However, if they choose different industries, then their returns are independent, that is, $\rho=0$. Note that the individual probability of each bank succeeding or failing $\left(\alpha_{t}\right.$ and $\left(1-\alpha_{t}\right)$ at time $t$, respectively) is independent of the inter-bank correlation. We focus on the joint choice of banks and hence denote $x_{i}$ 's simply as $x$.

This gives us the following probabilities for the number of bank failures at $t=1$. When $x=0$, banks invest in independent industries and we obtain a Binomial distribution for the number of bank failures:

$$
\operatorname{Pr}(k)=C(n, k) \alpha_{0}^{n-k}\left(1-\alpha_{0}\right)^{k} \quad \text { for } k \in\{0,1, \ldots n\},
$$

where $C(n, k)$ is the number of combinations of $k$ objects from a total of $n$.

When $x=1$, banks invest in the common industry and we obtain:

$$
\operatorname{Pr}(k)=\left\{\begin{array}{ccl}
\alpha_{0} & \text { for } & k=0 \\
0 & \text { for } & k \in\{1, \ldots, n-1\} \\
1-\alpha_{0} & \text { for } & k=n
\end{array} .\right.
$$

Next, we analyze banks' choice of correlation in their investments under different policies the regulator employs.

\subsection{Inter-bank correlation under bailout policy}

In this section, we analyze banks' ex-ante choice of correlation when the regulator employs the ex-post optimal bailout policy. First, we derive banks' expected profits when they invest in idiosyncratic industries and the common industry, that is, when the inter-bank correlation $\rho$ equals 0 and 1 , respectively. We show that the level of correlation chosen by banks depends on the expected profit banks make from the purchase of failed banks' assets when they survive and the expected subsidy they receive through bailouts when they fail. In Proposition 4, we formally state the conditions under which banks choose to invest in the common industry.

In the first period, all banks are identical. Hence, we consider a representative bank. Formally, the objective of each bank is to choose the level of inter-bank correlation $\rho$ at date 0 that maximizes

$$
E\left(\pi_{1}(\rho)\right)+E\left(\pi_{2}(\rho)\right)
$$

where discounting has been ignored since it does not qualitatively affect the results. The expected payoff to the bank at date 0 from its first-period investment, $E\left(\pi_{1}\right)$, is

$$
E\left(\pi_{1}\right)=\alpha_{0}\left(R_{0}-r_{0}\right)
$$


which does not depend on the level of inter-bank correlation. Hence, banks only take into account the second-period profits when choosing $\rho$.

Note that when banks invest in the same industry, if the return is low, then all banks fail together and the regulator bails out (randomly picked) $b^{*}(n)$ of them taking an equity stake of $\beta$ in the bailed-out banks. Thus, the expected profit from the second-period investment is given as:

$$
E\left(\pi_{2}(1)\right)=\alpha_{0} E\left(\pi_{2}\right)+\left(1-\alpha_{0}\right)\left(\frac{b^{*}(n)}{n}\right)(1-\beta) E\left(\pi_{2}\right) .
$$

When banks invest in idiosyncratic industries, profitable opportunities from asset purchases may arise. Using the price function in Figure 3, we can see that when only few banks fail, $k \leq \underline{k}$, surviving banks pay full price for the acquired assets. Thus, banks profit from asset purchase only in states that exhibit cash-in-the-market pricing, that is, when $k>\underline{k}$. For $k \in\{\underline{k}+1, \ldots, \bar{k}\}$, each surviving bank captures a surplus from asset purchase that equals

$$
\begin{aligned}
& y\left(p^{*}\right) \cdot\left[\bar{p}-p^{*}\right] \\
= & \frac{k}{(n-k)} \cdot\left[\bar{p}-\frac{(n-k) l}{k}\right] .
\end{aligned}
$$

Note that for $k \leq \bar{k}$, all failed banks are purchased by surviving banks and bank owners of failed banks have no continuation payoffs.

For $k>\bar{k}$, the regulator bails out some of the failed banks and prices are sustained at $\underline{p}$. As a result, failed banks receive a bailout subsidy equal to

$$
\phi(k)=\frac{b^{*}(k)}{k} \cdot(1-\beta) E\left(\pi_{2}\right) .
$$

In this region, the surplus per unit of banking asset purchased is $(\bar{p}-\underline{p})=\alpha_{1} \Delta$, and each surviving bank captures a surplus equal to $\left[\frac{l}{p} \cdot\left(\alpha_{1} \Delta\right)\right]$. However, surviving banks do not receive any additional benefit as $k$ increases since for $k>\bar{k}$, they always use all their funds $l$ to purchase failed banks' assets at the same price $\underline{p}$.

Given this analysis, we can calculate $E\left(\pi_{2}(0)\right)$, which has returns from investments, asset purchase, and bailouts for different states in the second period (see equation (42) in the Appendix). Comparing this to $E\left(\pi_{2}(1)\right)$, we obtain the following result:

Proposition 4 Under the ex-post optimal bailout policy (characterized in Corollary 1), there exists a critical threshold $\beta^{*} \in(0,1)$ such that: 
(i) If the continuation moral hazard is severe, that is, $(1-\bar{\theta})<\beta^{*}$, then the regulator takes an equity stake of $\beta$ in the bailed-out bank(s), such that, $\beta \leq(1-\bar{\theta})<\beta^{*}$, and banks invest in the common industry.

(ii) If $(1-\bar{\theta}) \geqslant \beta^{*}$, then the regulator takes an equity stake $\beta$, such that $\beta^{*} \leqslant \beta \leqslant(1-\bar{\theta})$, and banks invest in different industries.

Proof: See Appendix.

Note that this result is in contrast to the case with no bailouts. Without bailouts, failed banks receive no subsidy from the regulator, whereas surviving banks capture some rents through asset purchase at discounted prices. As a result, without bailouts, banks always choose the low correlation. To summarize, while bailouts lower the ex-post allocation inefficiency, they may give banks incentives to herd, since bailouts occur only when a sufficiently large number of banks have failed. The presence of continuation moral hazard implies that the regulator will not always be able to dilute the equity stake of bailed-out banks up to a level that induces banks ex ante to invest in different industries.

It can be shown that with the linear fiscal cost function, the optimal bailout policy (Corollary 1 ) implies that $\beta^{*}<1$ always. Furthermore, as the level of outsider funds, $w$, decreases, the second cash-in-the-market region becomes larger $(\overline{\bar{k}}$ decreases $)$. Thus, the region over which $\widehat{b}(k)$ banks are always bailed out increases (again, see Corollary 1 ). This increases the bailout subsidy for banks in states with a large number of bank failures, and aggravates bank incentives to herd. Formally, $\beta^{*}$ is decreasing in $w$ : as $w$ decreases, the regulator must hold a larger share in bailed-out banks to induce a low ex-ante correlation amongst banks. In turn, herding incentives prevail over a larger range of the continuation moral-hazard parameter $\bar{\theta}$.

This leads to the intuitively appealing conclusion that in economies where banking crises are likely to be economy-wide in nature, that is, accompanied by lower aggregate wealth, herding incentives of banks are likely to be more pronounced. Furthermore, from the standpoint of positive analysis, our model suggests that the too-many-to-fail (or too-many-to-liquidate) problem and the induced herding are likely to be more prevalent in banking systems where the governance of banks is poor: in other words, where agency problems (for example, fraud by bank owners) are more severe (high $\bar{\theta}$ ) so that banks are required in equilibrium to hold greater equity stakes for incentive reasons.

\subsection{Inter-bank correlation with liquidity provision}

While ex post the regulator is indifferent between bailout and the liquidity provision policies, these two policies may create different ex-ante incentives for banks. In particular, while bailouts induce herding incentives, liquidity provision can strengthen incentives for differentiation. Here, we analyze banks' ex-ante incentives under the liquidity provision policy. 
Note that when all banks fail, that is, $k=n$, there is no surviving bank to acquire failed banks' assets and the regulator follows the ex-post optimal bailout policy. As a result, the expected profit for banks when they invest in the common industry $(x=1)$ is the same under the liquidity provision and bailout policies, and is given in equation (32).

The expected profit for banks when they invest in different industries can also be calculated as in the case of bailout policy. We do not repeat the derivation in the text but highlight the important differences. See equation (46) in the Appendix for the whole expression.

On the one hand, when the regulator follows the liquidity provision policy, surviving banks can acquire a larger amount of failed banks' assets. In particular, for $k>\bar{k}$, they can also acquire the $b^{*}(k)$ bailed-out banks, that is, each surviving bank acquires $\left(\frac{b^{*}(k)}{n-k}\right)$ additional units of banking assets using $(n-k) l$ of their funds. This gives them an extra surplus of

$$
\gamma(k)=\left(\frac{b^{*}(k)}{n-k}\right) \bar{p}
$$

from the asset purchase, relative to the case with bailouts.

However, under the liquidity provision policy, there are no bailouts (unless all banks fail), whereas under the ex-post optimal bailout policy, a failed bank is bailed out with probability $\left(\frac{b^{*}(k)}{k}\right)$, giving rise to a bailout subsidy for failed banks that is given by $\phi(k)$, for $k>\bar{k}$ (see equation (35)).

The following Proposition characterizes banks' choice of correlation under the liquidity provision policy.

Proposition 5 Under the liquidity provision policy characterized in equation (25), there exists a critical threshold $\beta_{l}^{*}$ such that:

(i) If the continuation moral hazard is severe, that is, $(1-\bar{\theta})<\beta_{l}^{*}$, then the regulator takes an equity stake of $\beta$ in the bailed-out bank(s), such that, $\beta \leq(1-\bar{\theta})<\beta_{l}^{*}$, and banks invest in the common industry.

(ii) If $(1-\bar{\theta}) \geqslant \beta_{l}^{*}$, then the regulator takes an equity stake $\beta$, such that $\beta_{l}^{*} \leqslant \beta \leqslant(1-\bar{\theta})$, and banks invest in different industries.

Proof: See Appendix.

With the linear fiscal cost function, under the liquidity provision policy, we have $\beta_{l}^{*}<1$ always. However, the outsiders' funds $w$ have a different effect on banks' herding incentives when the regulator employs the liquidity provision policy compared to the case with bailouts. Intuitively, for efficient allocation of assets, it is desirable to have as much liquidity within the surviving banks as possible relative to the liquidity within the outsiders. Recall that as the 
level of outsider funds, $w$, decreases, the second cash-in-the-market region becomes larger $(\overline{\bar{k}}$ decreases). Thus, the region over which the regulator provides liquidity to surviving banks widens. This increases the expected surplus surviving banks make from the asset purchase in states with a large number of bank failures, and mitigates bank incentives to herd. Formally, $\beta_{l}^{*}$ is decreasing in $w$ : as $w$ decreases, the regulator must provide liquidity to surviving banks over a larger range of failures. This makes asset purchases more profitable for surviving banks, that is, $E(\gamma)$ increases and the regulator can induce a low ex-ante correlation amongst banks by holding a smaller share in bailed-out banks. In turn, herding incentives can be mitigated over a larger range of the continuation moral-hazard parameter $\bar{\theta}$.

\subsection{Welfare analysis}

Having derived the response of banks to different regulatory policies, in terms of their choice of inter-bank correlation, we now analyze ex-ante welfare under this choice. As before, we start with analyzing ex-ante welfare under the bailout policy. To this end, we first derive the total expected output generated by the banking industry when the inter-bank correlation, $\rho$, equals 0 or 1 . We show that the inter-bank correlation affects welfare through the misallocation and fiscal costs that vary with the number of bank failures. Next, we state in Proposition 6 sufficient conditions under which the expected total output is maximized when banks operate in different industries. Finally, we show that the ex-post optimal bailout policy is not optimal from an ex-ante standpoint, and show in Proposition 8 that the ex-post optimal liquidity provision policy can mitigate this time-inconsistency problem.

Let $E\left(\Pi_{t}(\rho)\right)$ be the expected output generated by the banking sector at date $t$, net of liquidation and/or bailout costs. If banks invest in the same industry at date 0 , then with probability $\alpha_{0}$, all $n$ banks have the high return so that $E\left(\Pi_{1}(1)\right)=n \alpha_{0} R_{0}$. However, if they invest in different industries, then with probability $\operatorname{Pr}(k)=C(n, k) \alpha_{0}^{(n-k)}\left(1-\alpha_{0}\right)^{k}, k$ banks have the low return while the remaining $(n-k)$ have the high return. Thus,

$$
E\left(\Pi_{1}(0)\right)=R_{0} \sum_{k=0}^{n}(n-k) \operatorname{Pr}(k)=R_{0}\left[n-\sum_{k=0}^{n} k \operatorname{Pr}(k)\right] .
$$

Note that $\left[\sum_{k=0}^{n} k \operatorname{Pr}(k)\right]$ is the expected number of failed banks and is equal to $\left[\left(1-\alpha_{0}\right) n\right]$ for the Binomial distribution, so that, $E\left(\Pi_{1}(0)\right)=E\left(\Pi_{1}(1)\right)=n \alpha_{0} R_{0}$. Thus, total expected output in the first period is independent of the choice of inter-bank correlation.

In the second period, the number of banks that continue operating depends on the outcome of the first-period investments and the regulator's action.

If banks invest in the same industry, then with probability $\alpha_{0}$, they all succeed and continue operating in the second period; with probability $\left(1-\alpha_{0}\right)$, they all fail, $b^{*}(n)$ of them 
are bailed out by the regulator at a fiscal cost of $f\left(n r_{0}-\left(n-b^{*}(n)\right) p\right)$, and the remaining $\left(n-b^{*}(n)\right)$ failed banks' assets are sold to outsiders resulting a misallocation cost of $\left[\left(n-b^{*}(n)\right)\left(\alpha_{1} \Delta\right)\right]$. Thus,

$$
\begin{aligned}
E\left(\Pi_{2}(1)\right) & =\alpha_{0} n\left(\alpha_{1} R_{1}\right)+\left(1-\alpha_{0}\right)\left[n\left(\alpha_{1} R_{1}\right)-f\left(n r_{0}-\left(n-b^{*}(n)\right) \underline{p}\right)-\left(n-b^{*}(n)\right)\left(\alpha_{1} \Delta\right)\right] \\
& =n\left(\alpha_{1} R_{1}\right)-\left(1-\alpha_{0}\right)\left[f\left(n r_{0}-\left(n-b^{*}(n)\right) \underline{p}\right)+\left(n-b^{*}(n)\right)\left(\alpha_{1} \Delta\right)\right] .
\end{aligned}
$$

Next, consider the case where banks invest in different industries. From Proposition 2, we know that for $k>\bar{k}, b^{*}(k)$ banks are bailed out, $(n-k)$ surviving banks buy as many units of banking assets as possible with their available resources of $((n-k) l)$ units, and the remaining $\left[k-\left(\frac{(n-k) l}{\underline{p}}\right)-b^{*}(k)\right]$ banks are sold to outsiders. This gives us

$$
\begin{aligned}
E\left(\Pi_{2}(0)\right)= & n\left(\alpha_{1} R_{1}\right)-\sum_{k=1}^{\bar{k}} \operatorname{Pr}(k) f\left(k r_{0}-k \cdot p^{*}(k)\right)-\sum_{k=\bar{k}+1}^{n} \operatorname{Pr}(k) f\left(k r_{0}-\left(k-b^{*}(k)\right) \underline{p}\right)- \\
& -\left(\alpha_{1} \Delta\right) \cdot \sum_{k=\bar{k}+1}^{n} \operatorname{Pr}(k)\left[k-\left(\frac{(n-k) l}{\underline{p}}+b^{*}(k)\right)\right]
\end{aligned}
$$

Note that the last term represents the expected misallocation cost. The second and third terms represent the fiscal cost for small and large number of bank failures, respectively.

From a welfare point of view, the optimal level of correlation is $\rho=0$ when $E\left(\Pi_{2}(0)\right)>$ $E\left(\Pi_{2}(1)\right)$. For the following analysis, we compare $E\left(\Pi_{2}(1)\right)$ in equation $(38)$ and $E\left(\Pi_{2}(0)\right)$ in equation (39) term by term.

First, we compare the misallocation cost in these two cases. Note that the number of failed banks' assets that are purchased by outsiders (weakly) increases as the number of failures increase. Therefore the misallocation cost is maximum when all $n$ banks fail. When banks choose the high correlation, the probability that they all fail is $\left(1-\alpha_{0}\right)$, while, when they choose the low correlation, there is a positive misallocation cost with probability of at most $\left[\sum_{k=\bar{k}+1}^{n} \operatorname{Pr}(k)\right]$. Thus, $\left(1-\alpha_{0}\right) \geqslant\left[\sum_{k=\bar{k}+1}^{n} \operatorname{Pr}(k)\right]$ is a sufficient condition for the expected misallocation cost to be higher when banks' returns are perfectly correlated.

Next, note that the expected fiscal cost of deposit insurance net of proceeds from asset sales is strictly greater if banks choose the high correlation. To see this, recall that the expected number of bank failures is equal to $\left[\left(1-\alpha_{0}\right) n\right]$ for both the high and the low correlation cases. Hence, the expected amount of funds needed for deposit insurance is [(1- $\left.\left.\alpha_{0}\right) n r_{0}\right]$ in both cases. However, when banks choose the high correlation, if all banks fail, then the regulator collects only $\underline{p}$ per unit of failed banking assets from outsiders. In contrast, if banks choose the low correlation, then up to an intermediate number of failures, $\bar{k}$, surviving banks are able to pay a price that is higher than $\underline{p}$. Thus, expected proceeds from asset sales are 
greater when banks choose the low correlation. Thus, $\left(1-\alpha_{0}\right) \geqslant\left[\sum_{k=\bar{k}+1}^{n} \operatorname{Pr}(k)\right]$ is in fact a sufficient condition for low correlation to dominate high correlation from an overall welfare perspective. For example, if $\bar{k} \geqslant n / 2$ (a condition that simplifies to $l \geq \underline{p}$ ), then $\alpha_{0}<1 / 2$ is sufficient to obtain that the socially optimal level of correlation is $\rho=0$.

Hence, we obtain the following formal result.

Proposition 6 For all $\alpha_{0}$ such that $\alpha_{0}<\left(\sum_{k=0}^{\bar{k}} \operatorname{Pr}(k)\right)$, the expected total output of the banking sector at date 0 (net of any anticipated costs of liquidations and bailouts) is maximized when banks operate in different industries, that is, when $\rho=0$.

\section{Proof: See Appendix.}

We showed that when the likelihood of bank failures is sufficiently high, social welfare is maximized when banks invest in different industries. Thus, the regulator may wish to implement "hard" closure policies, such as liquidating a sufficient number of banks in order to create incentives for banks to choose the low correlation. ${ }^{12}$ These policies may however not be ex-post optimal. For example, conditional upon reaching states where the number of bank failures is large, liquidation of banks may not be credible if bailout costs are smaller than liquidation costs. Another way the regulator can induce low correlation among banks is by diluting the equity share of bailed-out banks (see Proposition 4). However, this may also lack commitment ex post: if the minimum dilution required to induce low correlation is sufficiently large, then such dilution may have adverse consequences for continuation moral hazard and banks may choose bad projects.

We formalize this trade-off below. In particular, we characterize the ex-ante optimal bailout policy assuming that the regulator can commit to ex-post implementation of this policy. We also examine when the ex-ante optimal policy is not subgame perfect and thus time-inconsistent.

If the regulator commits not to bail out more than a threshold number of banks, then banks may choose to invest in different industries. Thus, we focus on a bailout policy $\widetilde{b}^{*}(k)=$ $\min \left\{b^{*}(k), \widetilde{b}\right\}$, where $\widetilde{b}$ is the maximum number of bank bailouts that implements the low correlation and $b^{*}(k)$ is the ex-post optimal bailout policy (see Figure 6 ). Note that a policy that never bails out banks $(\widetilde{b}=0)$ always implements the low correlation. Hence, $\widetilde{b}$ is welldefined. Since it is optimal ex post to bail out more than $\widetilde{b}$ banks, it suffices to concentrate the analysis on $\widetilde{b}^{*}(k)$ among the set of bailout strategies that implements the low correlation. ${ }^{13}$

\footnotetext{
${ }^{12}$ We assume that the regulator cannot write contracts that "force" banks to adopt specific investment choices, that is, the regulator cannot impose regulation that is explicitly contingent on inter-bank correlation.

${ }^{13}$ Note that this analysis is interesting only when the ex-post optimal level of bailouts, namely $b^{*}(k)$, is
} 
Note that it is optimal for the regulator to commit to not bailing out more than $\widetilde{b}$ banks if and only if the expected output generated by the banking industry is higher when banks choose the low correlation than the case where the regulator follows the ex-post optimal bailout policy and banks choose the high correlation. The trade-off is simple: ex post, the regulator cares only about continuation payoffs in states where $k>\bar{k}$, whereas ex ante, the regulator is willing to give up some of these payoffs in order to induce better incentives for banks to be less correlated. This gives us the following proposition on the time-inconsistency of ex-ante optimal policy.

Proposition 7 For all $\alpha_{0}$ such that $\alpha_{0} \leqslant\left[1-\left(\lambda\left(\frac{\underline{p}}{\tilde{p}^{*}(n)}\right) \sum_{k=\bar{k}+1}^{n} \operatorname{Pr}(k)\right)\right]$, where $\lambda=$ $\max \left\{\frac{\alpha_{1} \Delta}{F \underline{p}}, 1\right\}$, if the regulator can credibly commit to a bailout strategy ex ante, then it is optimal to commit to the strategy $\widetilde{b}^{*}(k)=\min \left\{b^{*}(k), \widetilde{b}\right\}$, where $\widetilde{b}$ is the maximum number of bank bailouts that implements the low correlation and $b^{*}(k)$ is defined in equation (20).

\section{Proof: See Appendix.}

The result in Proposition 7 is quite intuitive. For some values of $\alpha_{0}$, low correlation may be the socially optimal level of correlation. For those values, the regulator may need to commit to a strategy of excessive liquidation to give banks the incentives to choose the low correlation. This may however be too costly in terms of expected misallocation costs. Our analysis shows that a condition for this time-inconsistency to arise is that the likelihood of bank failures, $\left(1-\alpha_{0}\right)$, be sufficiently high.

Thus, under the ex-ante optimal bailout policy, the regulator has to commit to excessive liquidation of banks to prevent banks' herding incentives. This results in welfare losses ex post, in states where many banks fail. However, it can be possible that the regulator can mitigate this time-inconsistency problem using the liquidity provision policy instead of the bailout policy since with additional liquidity, surviving banks' surplus from asset purchases increases. Note that the liquidity provision policy characterized in equation (25) achieves the same level of ex-post social welfare as the ex-post optimal bailout policy. Thus, to mitigate herding incentives, the regulator may not have to resort to excessive liquidation in states where banking crises are systemic.

To illustrate this, we analyze the effect of the liquidity provision policy on banks' choice of correlation and show that the regulator can implement low correlation for a wider range of parameter values using this policy compared to the ex-post optimal bailout policy.

large enough to induce banks to choose the high correlation. In other cases, we would not observe timeinconsistency in the regulatory actions. More specifically, in these other cases, it is possible for the regulator to implement a low correlation among banks at date 0 without affecting the ex-post optimal closure policy. 
Recall that under the liquidity provision policy, surviving banks can receive the additional benefit of $\gamma(k)$ in equation (36) from the asset purchase since they can acquire more failed banks' assets using the liquidity they receive from the regulator. However, under this policy, there are no bailouts whereas under the ex-post optimal bailout policy, a failed bank receives an expected bailout subsidy of $\phi(k)$ given in equation (35). Hence, if $\gamma(k)>\phi(k)$, for all

$k>\bar{k}$, then it is sufficient to show that the expected gain for banks from the liquidity provision policy through asset purchases overweighs the expected loss of bailout subsidy. If this condition holds, then the regulator can implement the low correlation by taking a smaller stake in the bailed-out banks under the liquidity provision policy, that is, $\beta_{l}^{*} \leqslant \beta^{*}$. The following Proposition states a sufficient condition for this result to hold.

Proposition 8 For $l \geqslant \underline{p}$, we have $\beta_{l}^{*} \leqslant \beta^{*}$.

Proof: See Appendix.

First, note that this is only a sufficient condition that guarantees that $\gamma(k)>\phi(k)$, for all $k>\bar{k}$. The herding incentives are in fact mitigated under the liquidity provision policy for a larger range of parameter values. Second, the condition $l \geqslant p$ also simplifies to $\bar{k} \geqslant n / 2$, a condition under which it is socially optimal to have low inter-bank correlation for all $\alpha<1 / 2$.

\section{$5 \quad$ Empirical support and robustness}

In this section, we discuss how our paper relates to the resolution of bank failures in practice and provide support for the assumptions and results of our model from the empirical literature.

\subsection{Resolution of bank failures}

Our paper mainly focuses on different policies the regulator employs to resolve bank failures and compare these policies from an ex-ante and ex-post social welfare standpoint. In this section, we provide an overview of the policies regulators use in practice and relate these policies to the ones we analyze in our paper. Furthermore, we provide evidence from the resolution of banking crises for the policies used by the regulators.

\subsubsection{General overview}

One of the main results in this paper is that in individual bank failure states, the regulator should optimally let the surviving bank(s) acquire failed banks, whereas in multiple bank 
failures, it may sometimes be optimal for the regulator to intervene in the form of bailouts or liquidity provision to surviving banks. Below we provide a discussion of the policies regulators employ to intervene and resolve bank failures. See the report by the Basel Committee on Banking Supervision (BCBS, 2002) for a detailed discussion of the resolution policies.

In our paper, the regulator uses a variety of policy options to resolve bank failures including bailouts, sales to surviving banks, with and without government assistance such as liquidity provision and price-discrimination, and finally sales to outsiders. The policies we analyze in this paper broadly cover the spectrum of options regulators employ to resolve bank failures in practice. Below, we provide a brief discussion of these policy options.

Regulators use a range of policy options to resolve bank failures. On the one end, a bank can be kept open through an injection of capital, which would be a bailout by the regulator in our paper. On the other end, the troubled bank can be closed and liquidated, and, in our paper, this would correspond to a sale to outsiders. Between these two extremes, we have other possibilities such as sale of failed bank's assets to other banks with or without government assistance.

To resolve bank failures, regulators usually seek for a private sector resolution first, where the troubled bank is sold to another healthy institution. To minimize the fiscal cost of resolution, the regulator would ideally like to sell the bank to other banks without any government assistance. These arrangements are typically called merger and acquisition (M\&A) agreements. In our model, the regulator employs this policy when he decides to sell failed banks' assets to surviving banks without any liquidity provision or price-discrimination in the auction. When the regulator employs this policy, he can preserve the franchise value of the bank as a going concern, and yet can penalize the current owners, which would prevent moral hazard created by the regulator's actions. Note that for moderate number of failures, that is, for $k \leqslant \bar{k}$, the regulator employs this policy to resolve all bank failures in our model. However, during systemic crises $(k>\bar{k})$, because of the limited liquidity of surviving banks, this policy option may not be available and the regulator may have to resort to bailouts and sales may have to be supported by some sort of government assistance to attract potential buyers.

In this paper, for high number of failures, that is, for $k>\bar{k}$, the regulator employs the resolution policy of providing liquidity to surviving banks to be used for the asset purchase, which is shown to be equivalent to a specific form of price-discrimination policy where the regulator charges a lower price for surviving banks than the price it charges to the outsiders. Both of these policies are actually sale of failed banks' assets to surviving banks with some government assistance. In practice, regulators often employ similar policies, which are broadly classified as purchase and assumption (P\&A) agreements. In practice, $\mathrm{P} \& \mathrm{~A}$ agreements are often enhanced by government guarantees to attract buyers. For example, if the whole bank 
is purchased the acquirer may receive a government payment covering the difference between the market value of assets and liabilities. If only some deposits are purchased, the acquirer may be given the option of purchasing any of the others and get their pick of bank assets. Furthermore, P\&A agreements typically include some form of a put option, whereby the government promises to buy back the assets at a stated percentage of value within a specified time frame, or a contractual profit or loss-sharing agreement.

\subsubsection{Evidence}

In the introduction, we have provided some empirical evidence on the fact that regulatory actions taken in response to banking problems appear to depend on the performance of the whole banking system and the overall economy itself. Below we provide further evidence on this issue.

Santomero and Hoffman (1999) provide evidence on the existence of state-contingent regulatory actions. They argue that liquidation of banking assets would not be an appropriate strategy during systemic crises since fire-sale prices, large bid-ask spreads and the virtual lack of bids are common elements of a mass liquidation. Furthermore, during systemic crises, it would be too costly to close down a significant portion of the banking system in terms of investment disruption and consumer confidence, which justifies the state-contingent regulatory actions.

Kasa and Spiegel (1999) use bank closure data for the US for the period 1992 through 1997 and provide similar evidence. They compare an absolute closure rule, which closes banks when their asset/liability ratios fall below a given threshold with a relative closure rule, which closes banks when this ratio falls sufficiently below the industry average. A direct implication of the relative closure rule is forbearance when the banking industry as a whole

performs poorly. They find strong evidence that U.S. bank closures were based on relative performance during that period.

Finally, Brown and Dinc (2006) analyze failures among large banks in 21 major emerging markets in the 1990s and provide similar evidence. They show that the government decision to close or take over a failing bank depends on the financial health of other banks in that country. In particular, intervention is delayed if other banks in that country are also weak. They show that this too-many-to-fail effect is robust to controlling for bank-level characteristics, macroeconomic factors, political factors such as electoral cycle and potential IMF pressure, as well as worldwide time-specific factors.

On the resolution policies used by the regulators, Goodhart and Schoenmaker (1995) provide a cross-country survey of 104 bank failures in 24 different countries during the 1980s and early 1990s. They show that liquidation of failed banks has not been the rule but the 
exception. While 31 of the 104 banks were liquidated, 22 were bailed out using a rescue package and 49 were taken over by other banks.

Hawkins and Turner (1999) document evidence on the resolution methods used during the banking crises in the 1980s and 1990s for 23 countries (Table 12, page 40). They show that in 20 of these countries, government capital injection was used as one of the resolution policies. Furthermore, in 20 of these countries, domestic bank mergers were employed, while troubled banks were taken over by foreign banks in 9 countries.

Lindgren et.al. (1999) show that in all five crisis-stricken countries in the Asian in the late 1990s, public funds were used to recapitalize institutions and weak institutions were merged or taken over by other institutions (Table 6, page 31). Finally, Hoelscher et. al. (2003) provide evidence for the recent banking crises in 12 countries. They show that using public funds for the resolution of banking failures, mergers and purchase and assumption agreements were used as resolution policies in Argentina, Finland, Indonesia, Korea, Malaysia, Sweden, Thailand, Turkey and Venezuela.

In evidence for government assistance, such as price discrimination during the sale of failed institutions, to resolve failures, Santomero and Hoffman (1998) document that during the resolution of Savings and Loans crises, the Federal Savings and Loan Insurance Corporation (FSLIC) tried to merge failed thrifts with a stronger thrift, a process that involved noncompetitive bidding since it implied restrictions on non-thrift institutions to participate in the auctions. Furthermore, they document that FSLIC used incentives such as future payments of capital losses, yield maintenance guarantees and tax benefits to make it attractive for potential buyers to acquire troubled institutions.

\subsection{Evidence on herding}

A theoretical result of our analysis is that herding incentives of banks are stronger when the likelihood of default is high (Proposition ). In supporting evidence that studies correlation of different banks' assets through the correlation of their equity returns, Luengnaruemitchai and Wilcox (2004) find that during the period 1976 to 2001, banks in the US chose market and asset betas that clustered together more when banking sector was troubled, in terms of banks having low capital ratios. They find a lower standard deviation of bank betas in such times. Their interpretation of this finding is one of herding by banks to seek "safety in similarity": "[Banks] more tightly mimicked each other during troubled times." In troubled times, banks would be concerned more about regulatory bailouts than from an erosion of profit margins from mimicking each other: The likelihood of default on loans is relatively greater in such times compared to the likelihood of being repaid.

A number of studies have employed evidence from the over-exposure of banks to emerging 
market economies before the debt crisis of 1982-84. Guttentag and Herring (1984), for example, discuss three potential explanations. While their first two explanations are related to bounded rationality of banks, the only rational explanation they consider is that toomany-to-fail guarantees created incentives for banks to get over-exposed to risks in these countries. They suggest that deposit insurance, existence of lender-of-last-resort facilities as well as official support for debtor countries from international institutions such as the IMF gave banks the impression that they would be protected against risks. They also suggest that, by herding and keeping concentrations in line with each other, banks made sure that any problem that occurred would be a system-wide problem, not just the problem of an individual institution. Banks reasoned that, this, in turn, would make it harder for the regulatory authorities to blame or discriminate against individual institutions and would induce governments to take action to prevent the adverse consequences of a system-wide banking crisis.

While directly investing in similar industries is one way banks can increase the correlation of their returns, there are also under ways. For example, banks can achieve high levels of default correlation through inter-bank lending since this leads to the problems of one bank being transmitted to other banks in a contagion-type phenomenon, and indirectly increases the likelihood of bailout of the problem bank. Such alternative mechanisms are interesting to discuss and examine since they do not result in the erosion of profit margins (as in lending), a factor that could countervail the herding incentives in our model.

Another alternative for banks to lend to similar set of customers and to get exposed to similar risks without erosion of profit margins is to participate in syndicated loans. Through syndication, banks can ensure that they are more likely to receive regulatory subsidies when the loans perform poorly, affecting all syndicate members. Adams (1991) argues that before the emerging market debt crisis, banks comforted themselves by herding, thinking that as long as all banks made similar loans, any crisis would be system-wide and would force governments to bail out those countries in trouble. ${ }^{14}$ She also argues that syndicated loans acted as an important vehicle for herding and hundreds of billions of dollars in loans were syndicated between 1970 and 1982. On a similar point, Jain and Gupta (1987) also discuss the role of syndicated loans for bank herding during the emerging market debt crisis.

\subsection{Discussion: Separation of ownership and control}

Perhaps an important limitation of our modeling approach is the assumption of uniformity of ownership and control. In particular, we have assumed that when failed banks' assets are

\footnotetext{
${ }^{14}$ According to Pedro-Pablo Kuczynski, a former World Bank official, Peruvian cabinet minister, and later an investment banker with First Boston Corporation, "banks preferred to lend to the public sector, not for ideological reasons but because government guarantees eliminated commercial risk."
} 
acquired by outsiders, they are also managed by outsiders who are not as good as existing managers in creating value from these assets. This assumption also allows us to focus on the investment choices of owners (also the effective managers in our model) at date 0.

What would be the effect of allowing for separation of ownership and control in our model? In general, this would allow for the possibility that outside owners can control the failed banks' assets but employ the original managers to run at least some of these assets. In order for our results to go through, we need to assume that an entirely frictionless transfer of ownership is not possible. A straightforward way of introducing such a friction would be to assume that outside owners are fragmented and uncoordinated (in our model, they are competitive) and acquire the sold assets piecemeal rather than as ongoing concerns. For instance, a bank could be sold piecemeal whereby its branches in different states, its commercial and investment banking operations, its retail versus wholesale businesses, and perhaps even different slices of its loan portfolio, are allocated to different participants in the auction. The resulting separate entities would not then all be managed by the single manager or CEO of the original whole bank. Note that, empirically, piecemeal liquidations do result in lower bank values than do sales of banks as ongoing concerns (James, 1991).

In other words, sales to outsiders would result in loss of ongoing concern value for the bank as a whole, and also result in partial or full loss of control of the bank for the existing management. In contrast, sales to insiders preserve bank value but always result in change of management: the management of acquiring banks has the expertise to run assets of the failed bank as effectively as the old management. Finally, the bailout of a failed bank by the regulator is a change in ownership to a single outsider, namely the regulator. This preserves the bank value and also results in full retention of control by the existing management of the failed bank. Given these outcomes, bailouts are more attractive for existing management than are sales to insiders or outsiders. Since bailouts occur in states where many banks fail together and reduce the incidence of sales to outsiders, bank management would have ex-ante incentives to herd as in our benchmark model, in particular, when the likelihood of adverse shocks to assets is high. In contrast, old owners are wiped out regardless of whether their bank is sold to outsiders or insiders, or if it is bailed out.

We would like to acknowledge that this qualitative argument presents one set of assumptions under which the separation of ownership and control would continue to deliver similar results as the one we obtained in this paper. Our goal in abstracting from this separation has been to formulate a parsimonious yet rich framework for analyzing limited expertise, cash-in-the-market pricing, and induced regulatory policies. Embedding managerial agency problems fully in such a framework remains an important topic for future research. 


\section{Conclusion}

This paper analyzed optimal resolution policies during banking crises of varying adversity. As the number of failed banks increases, total funding capacity of surviving banks decreases. In turn, surviving banks may not be able to buy all failed banks at the fundamental price of their assets, as in the industry-equilibrium hypothesis of Shleifer and Vishny (1992) and in the cash-in-the-market pricing in Allen and Gale (1994, 1998). Thus, some failed banks would have to be liquidated to investors outside the banking sector, resulting in a loss of continuation values. In order to avoid this allocation inefficiency from there being "too many (banks) to liquidate," the regulator may find it ex-post optimal to bail out banks; in contrast, if only some banks fail, then these banks can be acquired by the surviving banks and no regulatory intervention is required. However, this ex-post optimal bailout policy induces banks to herd so that they are more likely to be bailed out. Thus, the genesis of inefficient systemic risk potentially lies in the ex-post optimal bailout policy of the regulator.

We show that this time-inconsistency problem cam be mitigated if ex post the regulator follows a policy of providing liquidity to surviving banks to assist the purchase of failed banks. This also constitutes an important policy implication of our paper. The liquidity provision

policy we recommend is akin to the lender-of-last-resort policy but different in that it involves assisting safe banks for efficient resolution of bank failures rather than assisting the failed banks themselves.

The framework developed in this paper is flexible and tractable to provide a foundation for examining several other aspects of financial crises and their resolution. For example, surviving banks are financially constrained in our model and use their first-period profits for asset purchases. It would be interesting to extend our model to endogenize banks' choice of available funds for the asset purchase, in particular, by allowing banks to choose ex ante a portfolio of liquid and illiquid assets. Such an extension can shed light on the relative levels of socially and privately optimal liquidity position of banks. 


\section{References}

Acharya, Viral (2001) A Theory of Systemic Risk and Design of Prudential Bank Regulation, Working Paper, New York University and London Business School.

Acharya, Viral, Sreedhar Bharath and Anand Srinivasan (2003) Understanding the Recovery Rates of Defaulted Securities, Working Paper, London Business School.

Acharya, Viral and Tanju Yorulmazer (2005) Limited Liability and Bank Herding, mimeo., London Business School.

Acharya, Viral and Tanju Yorulmazer (2004) Too Many to Fail - An Analysis of Timeinconsistency in Bank Closure Policies, Working Paper, London Business School.

Adams, Patricia (1991) Loose Lending, Corruption and the Third World's Environmental Legacy, Chapter 10.

Allen, Franklin and Douglas Gale (1994) Liquidity Preference, Market Participation and Asset Price Volatility, American Economic Review, 84, 933-955.

Allen, Franklin and Douglas Gale (1998) Optimal Financial Crises, Journal of Finance, 53, $1245-1284$.

Allen, Franklin and Douglas Gale (2000) Financial Contagion, Journal of Political Economy, $108,1-33$.

Bagehot, William (1873) Lombard Street: A Description of the Money Market, London: H. S. King.

Berger, Philip, Eli Ofek and Itzhak Swary (1996) Investor Valuation of the Abandonment Option, Journal of Financial Economics, 42, 257-287.

BCBS (2002) Supervisory Guidance on Dealing with Weak Banks, Report of the Task Force on Dealing with Weak Banks, BIS, March.

Brown, Craig O. and I. Serdar Dinc (2006) Too Many to Fail? Evidence of Regulatory Reluctance in Bank Failures when the Banking Sector is Weak, mimeo., University of Michigan.

Calomiris, Charles W. (1998) Blueprints for a Global Financial Architecture, Reform Proposals, International Monetary Fund.

Caprio, Gerard and Daniela Klingebiel (1996) Bank Insolvencies: Cross Country Experience, World Bank, Policy Research Working Paper No. 1620. 
Caprio, Gerard, Luc Laeven, and Ross Levine (2005) Governance and Bank Valuation, Working Paper, Department of Economics, Brown University.

Claessens, Stijn, Simeon Djankov and Daniela Klingebiel (1999) Financial Restructuring in East Asia: Halfway There?, World Bank, Financial Sector Discussion Paper No. 3.

Diamond, Douglas and Raghuram Rajan (2003) Liquidity Shortages and Banking Crises, Journal of Finance, forthcoming.

Freixas, Xavier (1999) Optimal Bail out Policy, Conditionality and Constructive Ambiguity, Working Paper, Universitat Pompeu Fabra.

Goodhart, Charles and Dirk Schoenmaker (1995) Should the Functions of Monetary Policy and Banking Supervision be Separated?, Oxford Economic Papers, 47, 539-560.

Guttentag, Jack and Richard Herring (1984) Commercial Bank Lending to Developing Countries: From Overlending to Underlending to Structural Reform, in International Debt and the Developing Countries, edited by Gordon Smith and John T. Cuddington, 129150, World Bank, Washington D.C.

Hart, Oliver and John Moore (1994) A Theory of Debt Based on the Inalienability of Human Capital, Quarterly Journal of Economics, 109(4), 841-879.

Hawkins and Turner (1999) Bank Restructuring in Practice: An Overview, BIS Policy Papers, No: 6, pages 6- 105.

Hoelscher, David S. and Marc Quintyn (2003) Managing Systemic Banking Crises, IMF Occasional Paper \# 224.

Hoggarth, Glenn, Reidhill, Jack and Peter Sinclair (2004) On the Resolution of Banking Crises: Theory and Evidence, Working Paper \#229, Bank of England.

Hoggarth, Glenn, Ricardo Reis and Victoria Saporta (2001) Cost of Banking Instability: Some Empirical Evidence, Working Paper \#144, Bank of England, London, UK.

Holmstrom, Bengt and Jean Tirole (1998) Private and Public Supply of Liquidity, Journal of Political Economy, 106(1), 1-40.

Honohan, Patrick and Daniela Klingebiel (2000) Controlling Fiscal Costs of Bank Crises, World Bank, Working Paper \#2441.

James, Christopher (1991) The Losses Realized in Bank Failures, Journal of Finance, 46(4), $1223-1242$. 
Kahn, Charles and João A. C. Santos (2005) Endogenous Financial Fragility and Bank Regulation, Working Paper, Federal Reserve Bank of New York.

Kasa, Kenneth and Mark Spiegel (1999) The Role of Relative Performance in Bank Closure Decisions, Working Paper, Federal Reserve Bank of San Francisco.

Lindgren, Carl-Johan. Tomas J.T. Balino, Charles Enoch, Anne-Marie Gulde, Marc Quinty and Leslie Teo (1999) Financial Sector Crisis Restructuring: Lessons from Asia, IMF Occasional Paper \# 188.

Luengnaruemitchai, Pipat and James A. Wilcox (2004) Procyclicality, Banks' Reporting Discretion, and "Safety in Similarity," in The New Basel Accord, edited by Benton E. Gup, South-Western Publishing, 151-175.

Mailath, George and Loretta Mester (1994) A Positive Analysis of Bank Closure, Journal of Financial Intermediation, 3, 272-299.

Mitchell, Janet (1997) Strategic Creditor Passivity, Bank Rescues, and Too Many to Fail, CEPR Working Paper \#1780.

Myers, Stewart and Nicholas Majluf (1984) Corporate Financing and Investment When Firms Have Information Shareholders Do Not Have, Journal of Financial Economics, $13,187-221$.

Penati, Alessandro and Aris Protopapadakis (1988) The Effect of Implicit Deposit Insurance on Banks' Portfolio Choices, with an Application to International 'Overexposure', Journal of Monetary Economics, 21(1), 107-126.

Perotti, Enrico and Javier Suarez (2002) Last Bank Standing: What do I Gain If You Fail?, European Economic Review, 46(09), 1599-1622.

Pulvino, Todd C. (1998) Do Asset Fire Sales Exist: An Empirical Investigation of Commercial Aircraft Sale Transactions, Journal of Finance, 53, 939-978.

Rajan, Raghuram (1994) Why Bank Credit Policies Fluctuate: A Theory and Some Evidence, Quarterly Journal of Economics, 109, 399-442.

Rochet, Jean-Charles and Jean Tirole (1996) Interbank Lending and Systemic Risk, Journal of Money, Credit and Banking, 28 (4), 733-762.

Santomero, Anthony and Paul Hoffman (1999) Problem Bank Resolution: Evaluating the Options, Working Paper, Financial Institutions Center, the Wharton School, University of Pennsylvania. 
Shleifer, Andrei and Robert Vishny (1992) Liquidation values and debt capacity: A market equilibrium approach, Journal of Finance, Vol. 47, 1343-1366.

Stromberg, Per (2000) Conflicts of Interest and Market Illiquidity in Bankruptcy Auctions: Theory and Tests, Journal of Finance, 55, 2641-2692.

Williamson, Oliver E. (1988) Corporate Finance and Corporate Governance, Journal of Finance, 43, 567-592.

Wilson, Robert (1979) Auctions of Shares, Quarterly Journal of Economics, 93(4), 675-689. 


\section{Appendix}

\section{A.1 Proofs:}

Proof for profitability of asset purchase: Note that asset purchase by a surviving bank is possible only when banks invest in different industries.

At price $p$, a surviving bank can purchase $\left(\frac{l}{p}\right)$ units of failed banks' assets. Thus in its investment portfolio, the bank will have a total of $\left(\frac{l}{p}+1\right)$ units of banking assets. Let $x_{j}$ be the units of assets of the $j^{\text {th }}$ bank in the bank's portfolio after asset purchase and let $x=\sum_{j} x_{j}$. Note that even though there is no deposit insurance in the second period, depositors always receive their reservation value of 1 , in expected terms. Let $\widetilde{r}_{1}$ be the random return depositors receive from the bank, where $E\left(\widetilde{r}_{1}\right)=1$. We can write the bank's expected profit as

$$
E\left(\pi_{2}\right)=E\left[\sum_{j} x_{j} \widetilde{R}_{j}-p(x-1)-x \widetilde{r}_{1}\right]=E\left[\sum_{j} x_{j} \widetilde{R}_{j}\right]-x-p(x-1) .
$$

By independence of $\widetilde{R}_{j}$, we can write

$$
\begin{aligned}
E\left(\pi_{2}\right) & =\sum_{j} x_{j} E\left(\widetilde{R}_{j}\right)-x-p(x-1)=\sum_{j} x_{j}\left(\alpha_{1} R_{1}\right)-x-p(x-1) \\
& =x\left(\alpha_{1} R_{1}-1\right)-p(x-1)=(x-1)\left(\alpha_{1} R_{1}-1-p\right)+\alpha_{1} R_{1}-1 .
\end{aligned}
$$

Note that if the bank does not purchase the assets, the expected profit is $\left(\alpha_{1} R_{1}-1\right)$. Thus, for $p<\alpha_{1} R_{1}-1$, the bank uses all its available funds for the asset purchase. ${ }^{15} \diamond$

Proof of Proposition 4: For $k \leqslant \bar{k}$, no failed bank is bailed out, all failed banks' assets are purchased by surviving banks (capturing a surplus of $\left[\left(\frac{k}{n-k}\right) E\left(\pi_{2}\right)-l\right]$ ), and a failed bank's expected second period profit is equal to zero.

For $k>\bar{k}, b^{*}(k)$ banks are bailed out, where $b^{*}(k)$ is given in Corollary 1 . The expected continuation payoff for a bailed-out bank is $(1-\beta) E\left(\pi_{2}\right)$, where $\beta$ is the regulator's share, and each surviving bank captures a surplus of $\left[\frac{l}{p} \cdot\left(\alpha_{1} \Delta\right)\right]$.

\footnotetext{
${ }^{15}$ Note that this proof assumes that there is no deposit insurance at $t=2$, an assumption that does not affect any of our other results. With insurance at $t=2$, acquiring uncorrelated assets can coinsure depositors, lowering the value of the deposit-insurance option for bank owners (this happens when $\alpha_{1}$ is sufficiently small). This implies that the market for banking assets will clear only at lower prices compared to the case with no deposit insurance. This will make the effect of cash-in-the-market pricing even stronger, in particular, it will make bailouts more likely. Note, however, that if there was a fairly-priced deposit insurance premium collected at the beginning of the second period but after the asset purchases have taken place, then the effective cost of borrowing deposits remains the same for banks. In this case, the current proof for the profitability of the asset purchase still holds.
} 
If banks choose $x=0$, their returns are independent and we have a Binomial distribution for the number of failures, $k$. We can write banks' expected profit $E\left(\pi_{2}(0)\right)$ as:

$$
\begin{aligned}
= & \alpha_{0}\left[E\left(\pi_{2}\right)+\sum_{j=\underline{k}+1}^{\bar{k}}\left[P(j)\left[\left(\frac{j}{n-j}\right) E\left(\pi_{2}\right)-l\right]\right]+\right. \\
\alpha_{0} & {\left[\sum_{j=\bar{k}+1}^{n-1}\left[P(j)\left(\frac{l\left(\alpha_{1} \Delta\right)}{\underline{p}}\right)\right]\right]+\left(1-\alpha_{0}\right)\left[\sum_{j=\bar{k}}^{n-1}\left[P(j)\left(\frac{b^{*}(j+1)}{j+1}\right)(1-\beta) E\left(\pi_{2}\right)\right]\right], }
\end{aligned}
$$

where $j$ is the number of failures among the remaining $(n-1)$ banks and $P(j)$ is the corresponding probability for this event, when we exclude the bank that we calculate the expected profit for. For the Binomial distribution, we have that $P(j)=C(n-1, j) \alpha_{0}^{n-1-j}\left(1-\alpha_{0}\right)^{j}$.

If banks choose $x=1$, they are perfectly correlated and their expected return is:

$$
E\left(\pi_{2}(1)\right)=\alpha_{0} E\left(\pi_{2}\right)+\left(1-\alpha_{0}\right)\left(\frac{b^{*}(n)}{n}\right)(1-\beta) E\left(\pi_{2}\right),
$$

Next, we derive the critical equity share, denoted by $\beta^{*}$, which if taken by the regulator in each bailed-out bank, then banks would choose not to invest in the common industry.

Note that, banks choose $x=1$ if and only if $E\left(\pi_{2}(1)\right)-E\left(\pi_{2}(0)\right)>0$. Let $d(\beta)=$ $\left[E\left(\pi_{2}(1)\right)-E\left(\pi_{2}(0)\right)\right]$, where

$$
\begin{aligned}
d(\beta)= & \left(1-\alpha_{0}\right)(1-\beta) E\left(\pi_{2}\right)\left[\frac{b^{*}(n)}{n}-\sum_{j=\bar{k}}^{n-1}\left[P(j)\left(\frac{b^{*}(j+1)}{j+1}\right)\right]\right] \\
& -\alpha_{0}\left[\sum_{j=\underline{k}+1}^{\bar{k}}\left[P(j)\left[\left(\frac{j}{n-j}\right) E\left(\pi_{2}\right)-l\right]\right]+\sum_{j=\bar{k}+1}^{n-1}\left[P(j)\left(\frac{l\left(\alpha_{1} \Delta\right)}{\underline{p}}\right)\right]\right] .
\end{aligned}
$$

Note that only the first term depends on $\beta$. Also, note that $\left(\frac{b^{*}(k)}{k}\right)$ is increasing in $k$. Hence, $\left(\frac{b^{*}(n)}{n}\right)>\left(\frac{b^{*}(k)}{k}\right)$ for all $k \in\{0, \ldots, n-1\}$ and we have $\frac{\partial d}{\partial \beta}<0$. Thus, there exists a unique $\beta^{*}$ such that $\left[E\left(\pi_{2}(1)\right)-E\left(\pi_{2}(0)\right)\right]>0$ if and only if $\beta<\beta^{*}$, where

$$
\beta^{*}=1-\left[\frac{\alpha_{0}\left(\sum_{j=\underline{k}+1}^{\bar{k}}\left[P(j)\left[\left(\frac{j}{n-j}\right) E\left(\pi_{2}\right)-l\right]\right]+\sum_{j=\bar{k}+1}^{n-1}\left[P(j)\left(\frac{l\left(\alpha_{1} \Delta\right)}{\underline{p}}\right)\right]\right)}{\left(1-\alpha_{0}\right) E\left(\pi_{2}\right)\left[\frac{b^{*}(n)}{n}-\sum_{j=\bar{k}}^{n-1}\left[P(j)\left(\frac{b^{*}(j+1)}{j+1}\right)\right]\right]}\right]
$$

For $\beta^{*} \leqslant 0$, banks always choose $x=0$. For $\beta^{*}>0$, banks choose $x=1$ when $\beta<\beta^{*}$, otherwise, they choose $x=0$. 
Note however that the regulator will ex post never take a share $\beta$ that exceeds $(1-\bar{\theta})$ : it is better to liquidate the bank than to have it run inefficiently by bank owners due to poor provision of incentives. Thus, if $(1-\bar{\theta})<\beta^{*}$, then the regulator's share $\beta$ is smaller than $\beta^{*}$ in the subgame perfect equilibrium, and banks choose $x=1$. If $(1-\bar{\theta}) \geq \beta^{*}$, then the regulator takes a share $\beta$ between $\beta^{*}$ and $(1-\bar{\theta})$ and this induces banks to choose $x=0$.

Also, note that with the linear cost function, $\left(\frac{b^{*}(k)}{k}\right)$ is increasing in $k$, whereby the denominator in the last term in equation (44) is positive, and, in turn, $\beta^{*}<1$ always.

Proof of Proposition 5: Note that under the liquidity provision policy characterized in equation (25), for $k>\bar{k}$, each surviving bank can acquire $\left(\frac{l}{\underline{p}}+\frac{b^{*}(k)}{(n-k)}\right)$ units of failed banks' assets, where $b^{*}(k)$ is given by the ex-post optimal bailout policy. Hence, if banks choose $x=0$, we can write each bank's expected profit $E\left(\pi_{2}^{l}(0)\right)$ as:

$$
\begin{aligned}
= & \alpha_{0}\left[E\left(\pi_{2}\right)+\sum_{j=\underline{k}+1}^{\bar{k}}\left[P(j)\left[\left(\frac{j}{(n-j)}\right) \bar{p}-l\right]\right]+\right. \\
& \alpha_{0}\left[\sum_{j=\bar{k}+1}^{n-1}\left[P(j)\left[\left(\frac{l}{\underline{p}}+\frac{b^{*}(j)}{(n-j)}\right) \bar{p}-l\right]\right]\right]+\left(1-\alpha_{0}\right)^{n}\left(\frac{b^{*}(n)}{n}\right)(1-\beta) E\left(\pi_{2}\right),
\end{aligned}
$$

where $j$ is the number of failures among the remaining $(n-1)$ banks and $P(j)$ is the corresponding probability for this event, when we exclude the bank that we calculate the expected profit for.

If banks choose $x=1$, they are perfectly correlated and their expected return is:

$$
E\left(\pi_{2}^{l}(1)\right)=\alpha_{0} E\left(\pi_{2}\right)+\left(1-\alpha_{0}\right)\left(\frac{b^{*}(n)}{n}\right)(1-\beta) E\left(\pi_{2}\right) .
$$

Note that, banks choose $x=1$ if and only if $E\left(\pi_{2}(1)\right)>E\left(\pi_{2}(0)\right)$. Let $d_{l}(\beta)=$ $\left[E\left(\pi_{2}(1)\right)-E\left(\pi_{2}(0)\right)\right]$, where

$$
\begin{aligned}
d_{l}(\beta) & =\left(1-\alpha_{0}\right)\left(1-\left(1-\alpha_{0}\right)^{n-1}\right)\left(\frac{b^{*}(n)}{n}\right)(1-\beta) E\left(\pi_{2}\right) \\
& -\alpha_{0}\left[\sum_{j=\underline{k}+1}^{\bar{k}}\left[P(j)\left[\left(\frac{j}{(n-j)}\right) \bar{p}-l\right]\right]+\sum_{j=\bar{k}+1}^{n-1}\left[P(j)\left[\left(\frac{l}{\underline{p}}+\frac{b^{*}(j)}{(n-j)}\right) \bar{p}-l\right]\right]\right] .
\end{aligned}
$$

Note that only the first term depends on $\beta$ and we have $\frac{\partial d_{l}}{\partial \beta}<0$. Thus, $E\left(\pi_{2}(1)\right)-E\left(\pi_{2}(0)\right)>0$ 
if and only if $\beta<\beta_{l}^{*}$, where

$$
\beta_{l}^{*}=1-\left[\frac{\alpha_{0}\left[\sum_{j=\underline{k}+1}^{\bar{k}}\left[P(j)\left[\left(\frac{j}{(n-j)}\right) E\left(\pi_{2}\right)-l\right]\right]+\sum_{j=\bar{k}+1}^{n-1}\left[P(j)\left[\left(\frac{l}{\underline{p}}+\frac{b^{*}(j)}{(n-j)}\right) \bar{p}-l\right]\right]\right]}{\left(1-\alpha_{0}\right)\left(1-\left(1-\alpha_{0}\right)^{n-1}\right)\left(\frac{b^{*}(n)}{n}\right) E\left(\pi_{2}\right)}\right] .
$$

For $\beta_{l}^{*}>0$, banks choose $x=1$ when $\beta<\beta_{l}^{*}$, otherwise, they choose $x=0$.

Note however that the regulator will ex post never take a share $\beta$ that exceeds $(1-\bar{\theta})$ : it is better to liquidate the bank than to have it run inefficiently by bank owners due to poor provision of incentives. Thus, if $(1-\bar{\theta})<\beta_{l}^{*}$, then the regulator's share $\beta$ is smaller than $\beta_{l}^{*}$ in the subgame perfect equilibrium, and banks choose $x=1$. If $(1-\bar{\theta}) \geq \beta_{l}^{*}$, then the regulator takes a share $\beta$ between $\beta_{l}^{*}$ and $(1-\bar{\theta})$ and this induces banks to choose $x=0$.

Note that the denominator in the last term in the above expression for $\beta_{l}^{*}$ is positive, and, in turn, $\beta_{l}^{*}<1$ always. For $\beta_{l}^{*} \leqslant 0$, banks always choose $x=0$.

Proof of Proposition 6: The socially optimal level of correlation is $\rho=0$ when $E\left(\Pi_{2}(0)\right)>$ $E\left(\Pi_{2}(1)\right)$. With the linear fiscal cost function $f(c)=F c$, we have

$$
E\left(\Pi_{2}(1)\right)=n\left(\alpha_{1} R_{1}\right)-\underbrace{\left(1-\alpha_{0}\right)\left[n F r_{0}\right]}_{\text {expected cost of insurance }}+F \underbrace{\left(1-\alpha_{0}\right)\left[\left(n-b^{*}(n)\right) p\right]}_{\text {expected recovery from asset sales }}+\underbrace{\left(1-\alpha_{0}\right)\left[\left(n-b^{*}(n)\right)\left(\alpha_{1} \Delta\right)\right]}_{\text {expected misallocation cost }},
$$

and

$$
\begin{aligned}
E\left(\Pi_{2}(0)\right)= & n\left(\alpha_{1} R_{1}\right)-\underbrace{\sum_{k=1}^{n} \operatorname{Pr}(k) k\left(F r_{0}\right)}_{\text {expected cost of insurance }}-\underbrace{\left[\sum_{k=\bar{k}+1}^{n} \operatorname{Pr}(k)\left(k-\frac{(n-k) l}{\underline{p}}-b^{*}(k)\right)\right]\left[\alpha_{1} \Delta\right]}_{\text {expected misallocation cost }} \\
& +F[\underbrace{\sum_{k=1}^{\bar{k}} \operatorname{Pr}(k)\left(k \cdot p^{*}(k)\right)+\sum_{k=\bar{k}+1}^{n} \operatorname{Pr}(k)\left(\left(k-b^{*}(k)\right) \underline{p}\right)}_{\text {expected recovery from asset sales }}] .
\end{aligned}
$$

For $E\left(\Pi_{2}(0)\right)$, we can write the expected cost of insurance as $\left(1-\alpha_{0}\right) n F r_{0}$. Note that this term is common in $E\left(\Pi_{2}(1)\right)$ and $E\left(\Pi_{2}(0)\right)$. 
Note that $p^{*}(k)>\underline{p}$ for $k=1, \ldots, \bar{k}$ and we can show that the expected recovery from asset sales when $\rho=0$ is greater than

$$
\underline{p}\left[\sum_{k=1}^{n} \operatorname{Pr}(k) k-\sum_{k=\bar{k}+1}^{n} \operatorname{Pr}(k) b^{*}(k)\right] \text {. }
$$

If $\left(1-\alpha_{0}\right) \geqslant\left[\sum_{k=\bar{k}+1}^{n} \operatorname{Pr}(k)\right]$, then the above expression is greater than the expected funds recovered from asset sales when $\rho=1$, which is equal to $\left(\left(1-\alpha_{0}\right)\left(n-b^{*}(n)\right) \underline{p}\right)$.

Note that using equations (20) and (21), we can show that the number of failed banks' assets that are sold to outsider (weakly) increases in $k$. Thus, $\left[k-\frac{(n-k) l}{\underline{p}}-b^{*}(k)\right] \leqslant(n-$ $\left.b^{*}(n)\right)$ for all $k=\bar{k}+1, \ldots, n-1$, and these two expressions are equal when $k=n$. Again, if $\left(1-\alpha_{0}\right) \geqslant\left[\sum_{k=\bar{k}+1}^{n} \operatorname{Pr}(k)\right]$, the expected cost of misallocation of failed banks' assets is greater when $\rho=1$.

Thus, if $\left(1-\alpha_{0}\right) \geqslant\left[\sum_{k=\widehat{k}+1}^{n} \operatorname{Pr}(k)\right]$, which can also be written as

$$
\alpha_{0} \leqslant\left[1-\sum_{k=\bar{k}+1}^{n} \operatorname{Pr}(k)\right]=\sum_{k=0}^{\bar{k}} \operatorname{Pr}(k) \text {, }
$$

then $E\left(\Pi_{2}(0)\right)>E\left(\Pi_{2}(1)\right)$ and the socially optimal level of correlation is $\rho=0$. $\diamond$

Proof of Proposition 7: We already know that when the regulator never bails out banks, banks choose the low correlation. Now, let $\widetilde{b}$ be the maximum number of bailouts, that is, the bailout strategy $\widetilde{b}^{*}(k)=\min \left\{\widetilde{b}^{*}(k), \widetilde{b}\right\}$, that induces the low correlation.

We find a sufficient condition under which, if the regulator can credibly commit to a strategy ex ante, he chooses not to bail out more than $\widetilde{b}$ failed banks.

Since the regulator bails out fewer banks under the strategy $\widetilde{b}^{*}(k)$ compared to the ex-post optimal strategy $b^{*}(k)$, the price of failed banks' assets could fall below $\underline{p}$ for sufficiently large number of failures. We denote the price function when the regulator follows strategy $\widetilde{b}^{*}(k)$ as $\widetilde{p}^{*}(k)$. Formally, for $k \in\{1, \ldots, \bar{k}\}$, we have $\widetilde{p}^{*}(k)=p^{*}(k)$, and, for $k>\bar{k}, \widetilde{p}^{*}(k)$ can take values less than $\underline{p}$.

If the regulator commits not to bail out more than $\widetilde{b}$ banks, banks choose the low corre- 
lation and the resulting expected output is given as:

$$
\begin{aligned}
E\left(\widetilde{\Pi}_{2}(0)\right)= & n\left(\alpha_{1} R_{1}\right)-\underbrace{\sum_{k=1}^{n} \operatorname{Pr}(k) k F r_{0}}_{\text {expected insurance cost }}-\underbrace{\left[\sum_{k=\bar{k}+1}^{n} \operatorname{Pr}(k)\left[k-\frac{(n-k) l}{\widetilde{p}^{*}(k)}-\widetilde{b}^{*}(k)\right]\right]\left[\alpha_{1} \Delta\right]}_{\text {expected misallocation cost }} \\
& +F[\underbrace{\left.\sum_{k=1}^{\bar{k}} \operatorname{Pr}(k)\left(k \cdot p^{*}(k)\right)+\sum_{k=\bar{k}+1}^{n} \operatorname{Pr}(k)\left(k-\widetilde{b}^{*}(k)\right) \widetilde{p}^{*}(k)\right)}_{\text {expected recovery from asset sales }}] .
\end{aligned}
$$

When the regulator chooses the ex-post optimal number of bailouts $b^{*}(k)$, banks choose the high correlation and we obtain:

$$
E\left(\Pi_{2}(1)\right)=n\left(\alpha_{1} R_{1}\right)-\left(1-\alpha_{0}\right)\left[f\left(n r_{0}-\left(n-b^{*}(n)\right) \underline{p}\right)+\left(n-b^{*}(n)\right)\left(\alpha_{1} \Delta\right)\right] .
$$

The socially optimal level of correlation is $\rho=0$ when $E\left(\widetilde{\Pi}_{2}(0)\right) \geqslant E\left(\Pi_{2}(1)\right)$.

For $E\left(\widetilde{\Pi}_{2}(0)\right)$, we can write the expected cost of insurance as $\left[\left(1-\alpha_{0}\right) n F r_{0}\right]$, which is common in $E\left(\Pi_{2}(1)\right)$ and $E\left(\widetilde{\Pi}_{2}(0)\right)$.

We first prove the case for $F \leqslant \frac{\alpha_{1} \Delta}{\underline{p}}$, where the ex-post optimal bailout strategy is given in equation (20) in Corollary 1. In this case, we have

$$
E\left(\Pi_{2}(1)\right)=n\left(\alpha_{1} R_{1}\right)-\left(1-\alpha_{0}\right) F n r_{0} .
$$

Thus, a sufficient condition to have $E\left(\widetilde{\Pi}_{2}(0)\right)>E\left(\Pi_{2}(1)\right)$ is

$$
\sum_{k=\bar{k}+1}^{n} \operatorname{Pr}(k)\left(k-\widetilde{b}^{*}(k)\right) \widetilde{p}^{*}(k)\left[F-\frac{\alpha_{1} \Delta}{\widetilde{p}^{*}(k)}\right]+\left(\alpha_{1} \Delta\right) \sum_{k=\bar{k}+1}^{n} \operatorname{Pr}(k)\left[\frac{(n-k) l}{\widetilde{p}^{*}(k)}\right]+F \sum_{k=1}^{\bar{k}} \operatorname{Pr}(k)\left(k \cdot p^{*}(k)\right) \geqslant 0 .
$$

Note that $\underline{p} \geqslant \widetilde{p}^{*}(k)$ for $k \in\{\bar{k}+1, \ldots, n\}$. Thus, $\left[\frac{(n-k) l}{\widetilde{p}^{*}(k)}\right] \geqslant\left[\frac{(n-k) l}{\underline{p}}\right]$. Note that $\left[F-\frac{\alpha_{1} \Delta}{\widetilde{p}^{*}(k)}\right] \leqslant$ 0 . Also, we have $\left(k-\widetilde{b}^{*}(k)\right) \leqslant k$, so that condition (57) is automatically satisfied when

$$
\sum_{k=\bar{k}+1}^{n} \operatorname{Pr}(k) k \underline{p}\left[F-\frac{\alpha_{1} \Delta}{\widetilde{p}^{*}(k)}\right]+\left(\alpha_{1} \Delta\right) \sum_{k=\bar{k}+1}^{n} \operatorname{Pr}(k)\left[\frac{(n-k) l}{\underline{p}}\right]+F \sum_{k=1}^{\bar{k}} \operatorname{Pr}(k)\left(k \cdot p^{*}(k)\right) \geqslant 0
$$


Since $\widetilde{p}^{*}(k) \geqslant p$ for $k \in\{1, \ldots, \bar{k}\}$, we can show that condition (58) is automatically satisfied when

$$
\left(1-\alpha_{0}\right) n F \underline{p}+\left(\alpha_{1} \Delta\right) \sum_{k=\bar{k}+1}^{n} \operatorname{Pr}(k) \underbrace{\left[\frac{(n-k) l}{\underline{p}}-\frac{k \underline{p}}{\widetilde{p}^{*}(k)}\right]}_{\geqslant-\frac{n \underline{p}}{\widetilde{p}^{*}(n)}\left(\operatorname{since} \widetilde{p}^{*}(n) \leqslant \widetilde{p}^{*}(k)\right)} \geqslant 0 .
$$

Thus, it is sufficient to have

$$
\left(1-\alpha_{0}\right) n F \underline{p} \geqslant\left(\alpha_{1} \Delta\right) \frac{n \underline{p}}{\widetilde{p}^{*}(n)} \sum_{k=\bar{k}+1}^{n} \operatorname{Pr}(k),
$$

which can be written as $\alpha_{0} \leqslant 1-\left[\lambda\left(\frac{\underline{p}}{\widetilde{p}^{*}(n)}\right) \sum_{k=\bar{k}+1}^{n} \operatorname{Pr}(k)\right]$, where $\lambda=\left(\frac{\alpha_{1} \Delta}{F \underline{p}}\right)$.

Next, we prove the case for $F>\frac{\alpha_{1} \Delta}{\underline{p}}$. As in the previous case, the term $\left[n E\left(\pi_{2}\right)-\left(1-\alpha_{0}\right) F n r_{0}\right]$ is common in $E\left(\Pi_{2}(1)\right)$ and $E\left(\widetilde{\Pi}_{2}(0)\right)$, thus we omit these terms. Using the ex-post optimal bailout strategy in equation $(21)$, we get

$$
E\left(\Pi_{2}(1)\right)=\left(1-\alpha_{0}\right) w\left(F-\frac{\alpha_{1} \Delta}{\underline{p}}\right) .
$$

We also have

$$
\begin{aligned}
E\left(\widetilde{\Pi}_{2}(0)\right)= & -\left[\alpha_{1} \Delta\right]\left[\sum_{k=\bar{k}+1}^{n} \operatorname{Pr}(k)\left[k-\frac{(n-k) l}{\widetilde{p}^{*}(k)}-\widetilde{b}^{*}(k)\right]\right] \\
& \left.+F\left[\sum_{k=1}^{\bar{k}} \operatorname{Pr}(k)\left(k \cdot p^{*}(k)\right)+\sum_{k=\bar{k}+1}^{n} \operatorname{Pr}(k)\left(k-\widetilde{b}^{*}(k)\right) \widetilde{p}^{*}(k)\right)\right] .
\end{aligned}
$$

Note that $p^{*}(k) \geqslant \widetilde{p}^{*}(k) \geqslant \widetilde{p}^{*}(n)=\frac{w}{n-\tilde{b}}$, for all $k \in\{1, \ldots, n\}$. Using this, we can get a sufficient condition as:

$$
\begin{aligned}
&\left(1-\alpha_{0}\right) w\left(F-\frac{\alpha_{1} \Delta}{\underline{p}}\right) \\
&<-\left[\alpha_{1} \Delta\right][\sum_{k=\bar{k}+1}^{n} \operatorname{Pr}(k) \underbrace{\left[k-\frac{(n-k) l}{\widetilde{p}^{*}(k)}\right]}_{\leqslant n}]+\left(1-\alpha_{0}\right) w\left(\frac{n F}{(n-\tilde{b})}\right) \\
&-\sum_{k=\bar{k}+1}^{n} \operatorname{Pr}(k) \widetilde{b}^{*}(k)\left[F \widetilde{p}^{*}(k)-\alpha_{1} \Delta\right]
\end{aligned}
$$


which can be written as

$$
\left(1-\alpha_{0}\right) w\left(\frac{F \widetilde{b}}{(n-\tilde{b})}+\frac{\alpha_{1} \Delta}{\underline{p}}\right)>\left[\alpha_{1} \Delta\right]\left[\sum_{k=\bar{k}+1}^{n} \operatorname{Pr}(k) n\right]+\sum_{k=\bar{k}+1}^{n} \operatorname{Pr}(k) \widetilde{b}^{*}(k)\left[F \widetilde{p}^{*}(k)-\alpha_{1} \Delta\right],
$$

since $\widetilde{b}<n$.

Since $\widetilde{p}^{*}(k) \leqslant \underline{p}$ for all $k \in\{k+1, \ldots, n\}$, we have:

$$
\left(1-\alpha_{0}\right) w\left(\frac{F \widetilde{b}}{(n-\widetilde{b})}+\frac{\alpha_{1} \Delta}{\underline{p}}\right)>\left[\alpha_{1} \Delta\right]\left[\sum_{k=\bar{k}+1}^{n} \operatorname{Pr}(k) n\right]+\sum_{k=\bar{k}+1}^{n} \operatorname{Pr}(k) \widetilde{b}^{*}(k)\left[F \underline{p}-\alpha_{1} \Delta\right],
$$

Also, $\widetilde{b}^{*}(k) \leqslant \widetilde{b}$, for all $k \in\{1, \ldots, n\}$. And, since $F>\frac{\alpha_{1} \Delta}{\underline{p}}$, it is sufficient to show

$$
\left(1-\alpha_{0}\right) w\left(\frac{F \widetilde{b}}{(n-\tilde{b})}+\frac{\alpha_{1} \Delta}{\underline{p}}\right)>\left[\sum_{k=\bar{k}+1}^{n} \operatorname{Pr}(k)\right]\left[(n-\widetilde{b})\left(\alpha_{1} \Delta\right)+\widetilde{b} F \underline{p}\right]
$$

which can be written as

$$
\left(1-\alpha_{0}\right)>\frac{\underline{p}(n-\widetilde{b})\left[(n-\widetilde{b})\left(\alpha_{1} \Delta\right)+\widetilde{b} F \underline{p}\right]}{w\left[(n-\widetilde{b})\left(\alpha_{1} \Delta\right)+\widetilde{b} F \underline{p}\right]}\left[\sum_{k=\bar{k}+1}^{n} \operatorname{Pr}(k)\right]=\frac{\underline{p}}{\widetilde{p}^{*}(n)}\left[\sum_{k=\bar{k}+1}^{n} \operatorname{Pr}(k)\right] .
$$

Hence, for $F>\frac{\alpha_{1} \Delta}{\underline{p}}$, a sufficient condition to obtain $E\left(\widetilde{\Pi}_{2}(0)\right) \geqslant E\left(\Pi_{2}(1)\right)$ is

$$
\alpha_{0}<1-\left[\frac{\underline{p}}{\widetilde{p}^{*}(n)}\left(\sum_{k=\bar{k}+1}^{n} \operatorname{Pr}(k)\right)\right]
$$

Thus, if the regulator can credibly commit to a strategy ex ante, then for $\alpha_{0}<1-$ $\left[\lambda\left(\frac{\underline{p}}{\widetilde{p}^{*}(n)}\right) \sum_{k=\bar{k}+1}^{n} \operatorname{Pr}(k)\right]$, where $\lambda=\max \left\{\frac{\alpha_{1} \Delta}{F \underline{p}}, 1\right\}$, he chooses not to bail out more than $\widetilde{b}$ failed banks, that induces banks to choose the low correlation ex ante. However, we showed earlier that this strategy is time-inconsistent. $\diamond$

Proof of Proposition 8: Recall from the proofs of Propositions 4 and 5 that

$$
\begin{aligned}
d(\beta) & =\left[E\left(\pi_{2}(1)\right)-E\left(\pi_{2}(0)\right)\right] \text { and } \\
d_{l}(\beta) & =\left[E\left(\pi_{2}^{l}(1)\right)-E\left(\pi_{2}^{l}(0)\right)\right] .
\end{aligned}
$$


Let $D(\beta)=d(\beta)-d_{l}(\beta)$. Note that under both the bailout and liquidity provision policies, the expected return for banks from investing in the common industry is the same, that is, $E\left(\pi_{2}^{l}(1)\right)=E\left(\pi_{2}(1)\right)$. Hence, we have

$$
D(\beta)=E\left(\pi_{2}^{l}(0)\right)-E\left(\pi_{2}(0)\right) .
$$

Recall that $\frac{\partial d}{\partial \beta}<0$ and $\frac{\partial d_{l}}{\partial \beta}<0$. Hence, $D(\beta) \geqslant 0$ for all $\beta$, implies that $\beta_{l}^{*} \leqslant \beta^{*}$.

Next, we find a sufficient condition under which $D(\beta) \geqslant 0$.

We have $D(\beta)=E\left(\pi_{2}^{l}(0)\right)-E\left(\pi_{2}(0)\right)$ given as:

$$
=\alpha_{0}\left[\sum_{j=\bar{k}+1}^{n-1}\left[P(j)\left[\left(\frac{b^{*}(j)}{n-j}\right) \bar{p}\right]\right]-\left(1-\alpha_{0}\right)\left[\sum_{j=\bar{k}}^{n-2}\left[P(j)\left(\frac{b^{*}(j+1)}{j+1}\right)(1-\beta) \bar{p}\right]\right],\right.
$$

where $j$ is the number of failures among the remaining $(n-1)$ banks and $P(j)$ is the corresponding probability, when we exclude the bank that we calculate the expected profit for. Note that we can write this as:

$$
\begin{aligned}
& =\sum_{k=\bar{k}+1}^{n-1}\left[\operatorname{Pr}(k)[\underbrace{\left(\frac{b^{*}(k)}{n-k}\right) \bar{p}}_{=\gamma(k)}]\right]-\left[\sum_{j=\bar{k}+1}^{n-1}\left[\operatorname{Pr}(k)[\underbrace{\left(\frac{b^{*}(k)}{k}\right)(1-\beta) \bar{p}}_{\phi(k)}]\right]\right. \\
& =\sum_{k=\bar{k}+1}^{n-1}[\operatorname{Pr}(k)[(\gamma(k)-\phi(k))]]
\end{aligned}
$$

where $\operatorname{Pr}(k)$ is the probability of having $k$ failed banks out of the $n$ banks. The benefit from the liquidity provision policy, which is denoted by $\gamma(k)$, arises from the extra units of failed banking assets a surviving bank can purchase. The cost of the liquidity provision policy, denoted by $\phi(k)$, is basically the forgone bailout subsidy.

Hence, a sufficient condition for $\left[E\left(\pi_{2}^{l}(0)\right)-E\left(\pi_{2}(0)\right)\right] \geqslant 0$ is $[\gamma(k)-\phi(k)] \geqslant 0$ for all $k \in\{\bar{k}+1, \ldots, n-1\}$. We have

$$
\begin{aligned}
\gamma(k)-\phi(k) & =\left[\left(\frac{b^{*}(k)}{(n-k)}\right)-\left(\frac{b^{*}(k)}{k}\right)(1-\beta)\right] \bar{p} \\
& =b^{*}(k) \bar{p}\left[\left(\frac{k-(n-k)(1-\beta)}{(n-k) k}\right)\right] .
\end{aligned}
$$

Note that $[\gamma(k)-\phi(k)]$ is increasing in $k$. Hence, if $[\gamma(\bar{k}+1)-\phi(\bar{k}+1)] \geqslant 0$, then $[\gamma(k)-\phi(k)] \geqslant$ 0 for all $k \in\{\bar{k}+1, \ldots, n-1\}$. Thus,

$$
(\bar{k}+1)-(n-(\bar{k}+1))(1-\beta) \geqslant 0,
$$


is a sufficient condition for $\left[E\left(\pi_{2}^{l}(0)\right)-E\left(\pi_{2}(0)\right)\right] \geqslant 0$.

Also, note that $(\bar{k}+1) \geqslant\left(\frac{n l}{l+\underline{p}}\right)$ from the expression for $\bar{k}$ from equation (9). And note that the expression in equation (74) is increasing in the number of failed banks so that the inequality in equation $(74)$ is satisfied for $(\bar{k}+1)$ if it is satisfied for $\left(\frac{n l}{l+\underline{p}}\right)$. Hence, we can show that the condition in equation (74) is satisfied when

$$
l-(1-\beta) \underline{p} \geqslant 0
$$

Hence, for $(1-\beta) \leqslant(l / \underline{p})$, we have $\gamma(k) \geqslant \phi(k)$, for all $k>\bar{k}$. A sufficient condition for this to hold for all $\beta \in[0,1]$ is $l \geqslant \underline{p}$. This guarantees that the expected profit from choosing idiosyncratic industries is higher when the regulator uses the liquidity provision policy instead of the ex-post optimal bailout policy. Hence, for $l \geqslant \underline{p}$, the regulator can induce banks to choose the low correlation for a wider range of parameter values when he uses the liquidity provision policy, that is, $\beta_{l}^{*} \leqslant \beta^{*}$. $\diamond$ 


\section{A.2 Extension: Pledgeability of future cash flows}

In this extension, we show that our results are robust to allowing surviving banks to issue equity to outsiders, when the number of failures is large. In particular, we allow banks to generate funds at $t=1$ against their profits from the second period investments. Recall that the expected profits from the second period investment equal $\bar{p}=\left(\alpha_{1}\left(R_{1}-r_{1}\right)\right)$. However, because of moral hazard, banks cannot generate the full value against their second-period profits, but only a proportion $\left((1-\bar{\theta}) p_{0}\right)$, where $p_{0}$ is the price of equity share in surviving banks, purchased by outsiders. As we show later, $p_{0}$ depends on the number of failed banks $k$ as well the price of the failed banks' assets.

When $k$ out of $n$ banks fail, the maximum amount of funding available with the surviving banks for the purchase of failed banks' assets, including funds that can be generated against future profits, is given as:

$$
L(k)=(n-k)\left[l+(1+m)(1-\bar{\theta}) p_{0}\right],
$$

where $m$ is the number of failed banks' assets that can be purchased by a surviving bank.

Note that the total liquidity available within the set of surviving banks for asset purchases is higher compared to the benchmark case for two reasons: They can raise additional funds against their own future profits as well as the future profits from assets they plan to purchase. As a result, the region over which we observe cash-in-the-market pricing starts at a larger number of bank failures compared to the benchmark case.

In this case, we have two markets: one for assets of failed banks and one for shares of surviving banks. To find the equilibrium prices and allocations in these two markets, we formally state the optimization problem that surviving banks and outsiders face.

Let $s$ be the number of shares issued by a surviving bank. Because of moral hazard we have: $s \leqslant(1+m)(1-\bar{\theta})$. If a surviving bank issues $s$ unit of shares at the price $p_{0}(k)$ and purchases $m$ units of failed banks' assets at the price $p^{*}(k)$, it makes an expected profit of $\left[m\left(\bar{p}-p^{*}(k)\right)-s\left(\bar{p}-p_{0}(k)\right)\right]$.

Note that in any equilibrium, $p_{0}(k)$ cannot exceed $\bar{p}$. Thus, we have $p_{0}(k) \leqslant \bar{p}$, and surviving banks issue equity just enough for the asset purchase, not more.

Using this, we can state a surviving bank's maximization problem as:

$$
\begin{aligned}
& \max _{m, s} m\left(\bar{p}-p^{*}(k)\right)-s\left(\bar{p}-p_{0}(k)\right) \\
& \text { s.t. } \quad s p_{0}(k)+l \geqslant m p^{*}(k) \\
& s \leqslant(1+m)(1-\bar{\theta})
\end{aligned}
$$

For $p_{0}(k) \leqslant p^{*}(k)$, surviving banks cannot make positive profits by issuing equity to

purchase failed banks' assets. Thus, when $p_{0}(k) \leqslant p^{*}(k), s=0$ and $m=\left[\frac{l}{p^{*}(k)}\right]$. And when 
$p_{0}(k)>p^{*}(k)$, surviving banks make positive profits from asset purchase using the funds they generate by issuing equity. Hence, they would like to issue as much equity as possible, that is, $s=(1+m)(1-\bar{\theta})$.

We can state outsiders' maximization problem in a similar way:

$$
\begin{array}{ll}
\max _{x, y} & x\left(\underline{p}-p^{*}(k)\right)+y\left(\bar{p}-p_{0}(k)\right) \\
\text { s.t. } & x p^{*}(k)+y p_{0}(k) \leqslant w
\end{array}
$$

where $x$ and $y$ represent the number of failed banking assets and the number of shares in surviving banks purchased by outsiders, respectively.

In this case, in addition to purchasing failed banks' assets, outsiders have the option to purchase shares in surviving banks. Thus, when the share price of surviving banks, $p_{0}(k)$, is relatively low compared to the price of failed banks' assets, $p^{*}(k)$, outsiders prefer to purchase shares in surviving banks. However, if $p^{*}(k)$ becomes low compared to $p_{0}(k)$, then outsiders may prefer to acquire failed banks' assets themselves, resulting in a misallocation cost.

When $p^{*}(k)>\underline{p}$, outsiders do not want to purchase failed banks' assets and $x\left(p_{0}, p^{*}\right)=0$.

When $p^{*}(k)<\underline{p}$, outsiders choose $x$ to maximize:

$$
\begin{aligned}
& x\left(\underline{p}-p^{*}(k)\right)+\left(\frac{\left(w-x p^{*}(k)\right)}{p_{0}(k)}\right)\left(\bar{p}-p_{0}(k)\right) \\
= & x\left(\underline{p}-\frac{p^{*}(k) \bar{p}}{p_{0}(k)}\right)+w\left(\frac{\bar{p}}{p_{0}(k)}-1\right) .
\end{aligned}
$$

Thus, if $p^{*}(k)<\underline{p}$ and $\underline{p} p_{0}(k)>\bar{p} p^{*}(k)$, then outsiders use all their funds for the asset purchase, that is $\bar{x}=\frac{\bar{w}}{p^{*}(k)}$. When $p^{*}(k)<\underline{p}$ and $\underline{p} p_{0}(k)<\bar{p} p^{*}(k)$, outsiders use all their funds for the equity purchase, that is $y=\frac{w}{p_{0}(k)}$, and when $\underline{p} p_{0}(k)=\bar{p} p^{*}(k)$, outsiders are indifferent between the equity and the asset purchase.

In equilibrium, demand for shares of surviving banks and assets of failed banks should equal their supply. Hence, we have the market clearing conditions:

$$
\begin{array}{lc}
(n-k) s=y\left(p_{0}, p^{*}\right) & \text { (equity market) } \\
(n-k) m+x\left(p_{0}, p^{*}\right)=k & \text { (asset market) }
\end{array}
$$

Note that, as in the auction for failed banks' assets, unless we specify conditions for allocating surviving banks' shares to outsiders, an abundance of equilibria arises. We concentrate on the equilibrium where the participation of outsiders in the equity market is maximum, which results in maximum prices for failed banks' assets and minimum misallocation costs. However, even in this setup, we show that for a large number of failures, outsiders prefer to acquire 
failed banking assets rather than shares of surviving banks, resulting in misallocation costs. We also show that for such a large number of failures, the share price of surviving banks falls below their fundamental value.

The price functions for failed banks' assets and for shares of surviving banks are formally stated in the following proposition and are illustrated in Figure 8 and 9.

Proposition 9 In equilibrium, we have:

(i) For $w \geqslant \bar{p} n(1-\theta)$, prices for assets of failed banks and shares of surviving banks are as follows:

$$
p^{*}(k)=\left\{\begin{array}{ccc}
\bar{p} & \text { for } & k \leqslant \widehat{k} \\
\frac{(n-k) l+n(1-\bar{\theta}) \bar{p}}{k} & \text { for } & \widehat{k}<k \leqslant \widehat{\widehat{k}} \\
\underline{p} & \text { for } & \widehat{\widehat{k}}<k \leqslant \overline{\bar{k}} \\
\frac{(n-k) l+w}{k} & \text { for } & k>\overline{\bar{k}}
\end{array}\right.
$$

and

$$
p_{0}(k)=\left\{\begin{array}{ccc}
\bar{p} & \text { for } \quad k \leqslant \overline{\bar{k}} \\
\mu\left[\frac{(n-k) l+w}{k}\right] & \text { for } \quad k>\overline{\bar{k}}
\end{array},\right.
$$

where $\widehat{k}=$ floor $\left(\frac{n[l+(1-\bar{\theta}) \bar{p}]}{l+\bar{p}}\right)$ and $\widehat{\widehat{k}}=$ floor $\left(\frac{n[l+(1-\bar{\theta}) \bar{p}]}{l+\underline{p}}\right)$.

(ii) For $w<\bar{p} n(1-\theta)$, prices for assets of failed banks and shares of surviving banks are as follows:

$$
p^{*}(k)=\left\{\begin{array}{ccc}
\bar{p} & \text { for } & k \leqslant \widetilde{k} \\
\frac{(n-k) l+w}{k} & \text { for } & k>\widetilde{k}
\end{array}\right.
$$

and

$$
p_{0}(k)=\left\{\begin{array}{ccc}
\bar{p} & \text { for } \\
\frac{w}{n(1-\bar{\theta})} & \left\{\begin{array}{cc}
\text { for } & k>\overline{\bar{k}} \text { and } \gamma<\left[\frac{w}{n(1-\bar{\theta})}\right] \\
\text { for } & k>\overline{\bar{k}}, \gamma>\left[\frac{w}{n(1-\bar{\theta})}\right] \text { and } k \text { small }
\end{array}\right. \\
\mu\left[\frac{(n-k) l+w}{k}\right] & \text { for } & k>\bar{k}, \gamma>\left[\frac{w}{n(1-\bar{\theta})}\right] \text { and } k \text { large }
\end{array},\right.
$$

where $\widetilde{k}=$ floor $\left(\frac{n l+w}{l+\bar{p}}\right)$. 


\section{Proof: See below.}

As Proposition 9 shows, the price of shares of surviving banks follow an interesting pattern. When the number of failures is large, cash-in-the-market pricing results in the price of failed banks' assets falling below the threshold value of outsiders, $\underline{p}$. Since purchasing failed banks' assets at such prices becomes profitable for outsiders, in equilibrium they must be compensated for purchasing shares in surviving banks. As a result, share price of surviving banks also falls below their fundamental value, $\bar{p}$. In other words, surviving banks can raise equity financing only at discounts. The resulting dilution limits their ability to raise such financing and purchase more of failed banks' assets. Thus, limited funds within the whole system and the resulting cash-in-the-market pricing affects not only the price of failed banks' assets but also the price of shares of surviving banks.

Proof of Proposition 9: For a better flow of arguments, we will prove the entire results in four different steps, rather than proving parts (i) and (ii) separately. The steps of the proof are organized in a way that lays down the results for four different regions of number of failed banks $k$.

Note that because of moral hazard, maximum units of equity that can be issued is $n(1-\bar{\theta})$. Thus, if $w \geqslant \bar{p} n(1-\bar{\theta})$, that is, part (i), then the funds within the outsiders is sufficient to keep the share price $p_{0}(k)$ at $\bar{p}$, had they decided to use their funds for the purchase of these shares.

(1) For $k \leqslant \underline{k}$, surviving banks' own liquidity is sufficient to bid the price for the failed banks' assets to $\bar{p}$. Since $p^{*}(k)=\bar{p}>\underline{p}$, we have $x=0$ and $m=\left[\frac{k}{n-k}\right]$. Surviving banks do not need any extra liquidity so they do not issue any equity, that is, $s=0, y=0$ and $p_{0}(k)=\bar{p}$.

(2) If $w<\bar{p} n(1-\bar{\theta})$, that is, part (ii), then for $\underline{k}<k \leqslant \widetilde{k}$, where

$$
\widetilde{k}=\text { floor }\left(\frac{n l+w}{l+\bar{p}}\right) \text {, }
$$

liquidity within the surviving banks and the liquidity they can raise by issuing shares to outsiders is sufficient to sustain the price for the failed banks' assets at $\bar{p}$, that is,

$$
(n-k) l+w \geqslant k \bar{p} \text {. }
$$

Since $p^{*}(k)=\bar{p}>\underline{p}$, we have $x=0$ and $m=\left[\frac{k}{n-k}\right]$. Each surviving bank issues enough equity, at $p_{0}(k)=\bar{p}$, to purchase $\left[\frac{k}{n-k}\right]$ units of failed banks' assets at $p^{*}(k)=\bar{p}$. Thus, we have

$$
\begin{aligned}
l+s \bar{p} & =\left[\frac{k}{n-k}\right] \bar{p}, \text { which gives us: } \\
s & =\left[\frac{k}{n-k}-\frac{l}{\bar{p}}\right] \text { and } y=\left[k-\frac{(n-k) l}{\bar{p}}\right] .
\end{aligned}
$$


Note that $\bar{p} \leqslant \frac{w}{y}=\left[\frac{w p}{k \bar{p}-(n-k) l}\right]$, since $w \geqslant[k \bar{p}-(n-k) l]$. Thus, $p_{0}(k)$ can be sustained at $\bar{p}$.

If $w \geqslant \bar{p} n(1-\bar{\theta})$, then for $\underline{k}<k \leqslant \widehat{k}$, where

$$
\widehat{k}=\text { floor }\left(\frac{n[l+(1-\bar{\theta}) \bar{p}]}{l+\bar{p}}\right) \text {, }
$$

total liquidity within the surviving banks' and the liquidity they can raise by issuing shares to outsiders is sufficient to sustain the price for the failed banks' assets at $\bar{p}$.

Since $p^{*}(k)=\bar{p}>\underline{p}$, we have $x=0$ and $m=\left[\frac{k}{n-k}\right]$. Each surviving bank issues enough equity, at $p_{0}(k)=\bar{p}$, to purchase $\left[\frac{k}{n-k}\right]$ units of failed banks' assets at $p^{*}(k)=\bar{p}$, that is,

$$
\begin{aligned}
l+s \bar{p} & =\left[\frac{k}{n-k}\right] \bar{p}, \text { which gives us: } \\
s & =\left[\frac{k}{n-k}-\frac{l}{\bar{p}}\right] \text { and } y=\left[k-\frac{(n-k) l}{\bar{p}}\right] .
\end{aligned}
$$

(3) If $w<\bar{p} n(1-\bar{\theta})$, then for $\widetilde{k}<k \leqslant \overline{\bar{k}}$, total liquidity within the surviving banks and the outsiders is sufficient to sustain the price for the failed banks' assets at least at $\underline{p}$, that is,

$$
(n-k) l+w \geqslant k \underline{p} .
$$

Since $p^{*}(k) \geqslant \underline{p}$, we have $x=0$ and $m=\left[\frac{k}{n-k}\right]$. Each surviving bank issues enough equity, at $p_{0}(k)=\bar{p}$, to purchase $\left[\frac{k}{n-k}\right]$ units of failed banks' assets at $p^{*}(k)=\left[\frac{(n-k) l+w}{k}\right]$, that is,

$$
\begin{aligned}
l+s \bar{p} & =\left[\frac{k}{n-k}\right] p^{*}(k), \text { which gives us } \\
s & =\left[\frac{w}{(n-k) \bar{p}}\right] \text { and } y=\left[\frac{w}{\bar{p}}\right]
\end{aligned}
$$

If $w \geqslant \bar{p} n(1-\bar{\theta})$, then for $\widehat{k}<k \leqslant \widehat{\widehat{k}}$, where

$$
\widehat{\widehat{k}}=\text { floor }\left(\frac{n[l+(1-\bar{\theta}) \bar{p}]}{l+\underline{p}}\right),
$$

liquidity within the surviving banks and the liquidity they can raise through equity issuance from outsiders is sufficient to sustain $p^{*}(k)$ at least at $\underline{p}$, that is,

$$
(n-k) l+n(1-\bar{\theta}) \bar{p} \geqslant k \underline{p} .
$$


Since $p^{*}(k) \geqslant \underline{p}$, we have $x=0$ and $m=\left[\frac{k}{n-k}\right]$. Each surviving bank issues enough equity, at $p_{0}(k)=\bar{p}$, to purchase $\left[\frac{k}{n-k}\right]$ units of failed banks' assets at $p^{*}(k)=\left[\frac{(n-k) l+n(1-\bar{\theta}) \bar{p}}{k}\right]$, that is,

$$
\begin{aligned}
l+s \bar{p} & =\left[\frac{k}{n-k}\right] p^{*}(k), \text { which gives us } \\
s & =\left[\frac{n(1-\bar{\theta})}{(n-k)}\right] \text { and } y=n(1-\bar{\theta}) .
\end{aligned}
$$

(4) If $w \geqslant \bar{p} n(1-\bar{\theta})$, then for $k>\widehat{\widehat{k}}$ (if $w<\bar{p} n(1-\bar{\theta})$, then for $k>\overline{\bar{k}}$ ), total liquidity within the surviving banks and the liquidity they can raise through equity issuance from outsiders is no longer sufficient to sustain $p^{*}(k)$ at $\underline{p}$. Since $p^{*}(k)<\underline{p}$, outsiders may prefer to participate in the market for failed banks' assets.

If $p^{*}(k)<\underline{p}$ and $\underline{p} p_{0}(k)>\bar{p} p^{*}(k)$, then outsiders use all their funds for the asset purchase, that is $x=\frac{w}{p^{*}(k)}$.

If $p^{*}(k)<\underline{p}$ and $\underline{p} p_{0}(k)<\bar{p} p^{*}(k)$, then outsiders use all their funds for the equity purchase, that is $y=\frac{w}{p_{0}(k)}$, and if $\underline{p} p_{0}(k)=\bar{p} p^{*}(k)$, outsiders are indifferent between the purchase of surviving banks' shares and the failed banks' assets.

Next, we look at each case separately, whether it could be sustained as an equilibrium. Let $\mu=\left[\frac{\bar{p}}{\underline{p}}\right]$.

a) For $\frac{p_{0}(k)}{p^{*}(k)}>\mu$, we have $y=0$ and $x=\frac{w}{p^{*}(k)}$. For the equity market to clear, we need $s=0$. However, this is possible only when $p_{0}(k) \leqslant p^{*}(k)$, which contradicts with $\frac{p_{0}(k)}{p^{*}(k)}>\mu$. Thus, this case cannot be an equilibrium.

b) For $\frac{p_{0}(k)}{p^{*}(k)}<\mu$, we have $y=\min \left\{n(1-\bar{\theta}),\left(\frac{w}{p_{0}(k)}\right)\right\}$ and $x=0$. Hence, for the asset market to clear, we have $m=\left[\frac{k}{(n-k)}\right]$.

For the equity market to clear, surviving banks need to issue equity, that is, $p_{0}(k)>p^{*}(k)$. In that case, surviving banks are willing to purchase as much failed banking assets as possible and issue as many shares as possible. Thus, we have $s=\frac{y}{(n-k)}$.

Note that when $w$ is high, that is, when $w>\bar{p} n(1-\bar{\theta})$, we have $p_{0}(k)=\bar{p}$. However, this contradicts with the initial conditions $p^{*}(k) \leqslant \underline{p}$ and $\frac{p_{0}(k)}{p^{*}(k)}<\mu$. Hence, this cannot be an equilibrium.

When $w$ is low, that is, when $w<\bar{p} n(1-\bar{\theta})$, we have $p_{0}(k)=\left[\frac{w}{n(1-\bar{\theta})}\right]$ and $p^{*}(k)=$ $\left[\frac{(n-k) l+w}{k}\right]$. Thus, we have $\frac{p_{0}(k)}{p^{*}(k)}=\left[\frac{w k}{n(1-\bar{\theta})[(n-k) l+w]}\right]$. Note that for $k=\overline{\bar{k}}$, we have $p^{*}(k)=\underline{p}$, 
and our initial condition is satisfied. Hence this case can be an equilibrium for relatively low values of $k \cdot{ }^{16}$ However, for large values of $k$, this may not be the case. For example, when $k=n$, we have $\frac{p_{0}(k)}{p^{*}(k)}=\frac{1}{(1-\bar{\theta})}$. Thus, when $\frac{1}{(1-\bar{\theta})}>\mu$, this cannot be an equilibrium for large enough values of $k$.

c) For $\frac{p_{0}(k)}{p^{*}(k)}=\mu$, outsiders are indifferent between purchasing assets of failed banks and shares of surviving banks. Since $p_{0}(k)>p^{*}(k)$, surviving banks would like to issue as much equity as possible, that is, $s=(1+m)(1-\bar{\theta})$. Thus, we have

$$
\begin{aligned}
s \mu p^{*}(k)+l & =m p^{*}(k), \text { which gives us: } \\
(n-k) s \mu p^{*}(k)+(n-k) l & =(n-k) m p^{*}(k) .
\end{aligned}
$$

For the equity market to clear, we need $(n-k) s=y$. For the asset market to clear, we need $x=k-(n-k) m$. Thus, we can write condition (86) as:

$$
\begin{aligned}
y \mu p^{*}(k)+(n-k) l & =(k-x) p^{*}(k), \text { which gives us: } \\
p^{*}(k) & =\frac{(n-k) l}{(k-x-y \mu)} .
\end{aligned}
$$

Note that for outsiders, we have $x p^{*}(k)+y p_{0}(k)=w$, which gives us:

$$
x+y \mu=\frac{w}{p^{*}(k)} .
$$

Using condition (89), we get:

$$
\begin{aligned}
& p^{*}(k)=\frac{[(n-k) l] p^{*}(k)}{\left(k p^{*}(k)-w\right)}, \text { which gives us: } \\
& p^{*}(k)=\left[\frac{(n-k) l+w}{k}\right] \text { and } p_{0}(k)=\mu\left[\frac{(n-k) l+w}{k}\right]
\end{aligned}
$$

For the equity market to clear, we need $n(1-\bar{\theta})=y+x(1-\bar{\theta})$, that is,

$$
x+\left[\frac{y}{(1-\bar{\theta})}\right]=n .
$$

We also have

$$
x+y \mu=\left[\frac{w}{p^{*}(k)}\right] .
$$

\footnotetext{
${ }^{16}$ Note that $\frac{p_{0}(k)}{p^{*}(k)}$ is increasing in $\mathrm{k}$.
} 
Solving equations (92) and (93) simultaneously, we get:

$$
y=\left[\frac{(n-k)[w+n l]}{(n-k) l+w}\right]\left[\frac{(1-\bar{\theta})}{1-\mu(1-\bar{\theta})}\right] .
$$

Using equation (94), we get:

$$
\begin{aligned}
x & =n-\left(\frac{y}{1-\bar{\theta}}\right)=n-\left[\frac{(n-k)(w+n l)}{[w+(n-k) l][1-(1-\bar{\theta}) \mu]}\right], \text { and } \\
(1+m) & =\frac{n-x}{n-k}=\frac{(w+n l)}{[w+(n-k) l][1-(1-\bar{\theta}) \mu]} .
\end{aligned}
$$

This characterizes the equilibrium in Proposition $9 . \diamond$ 


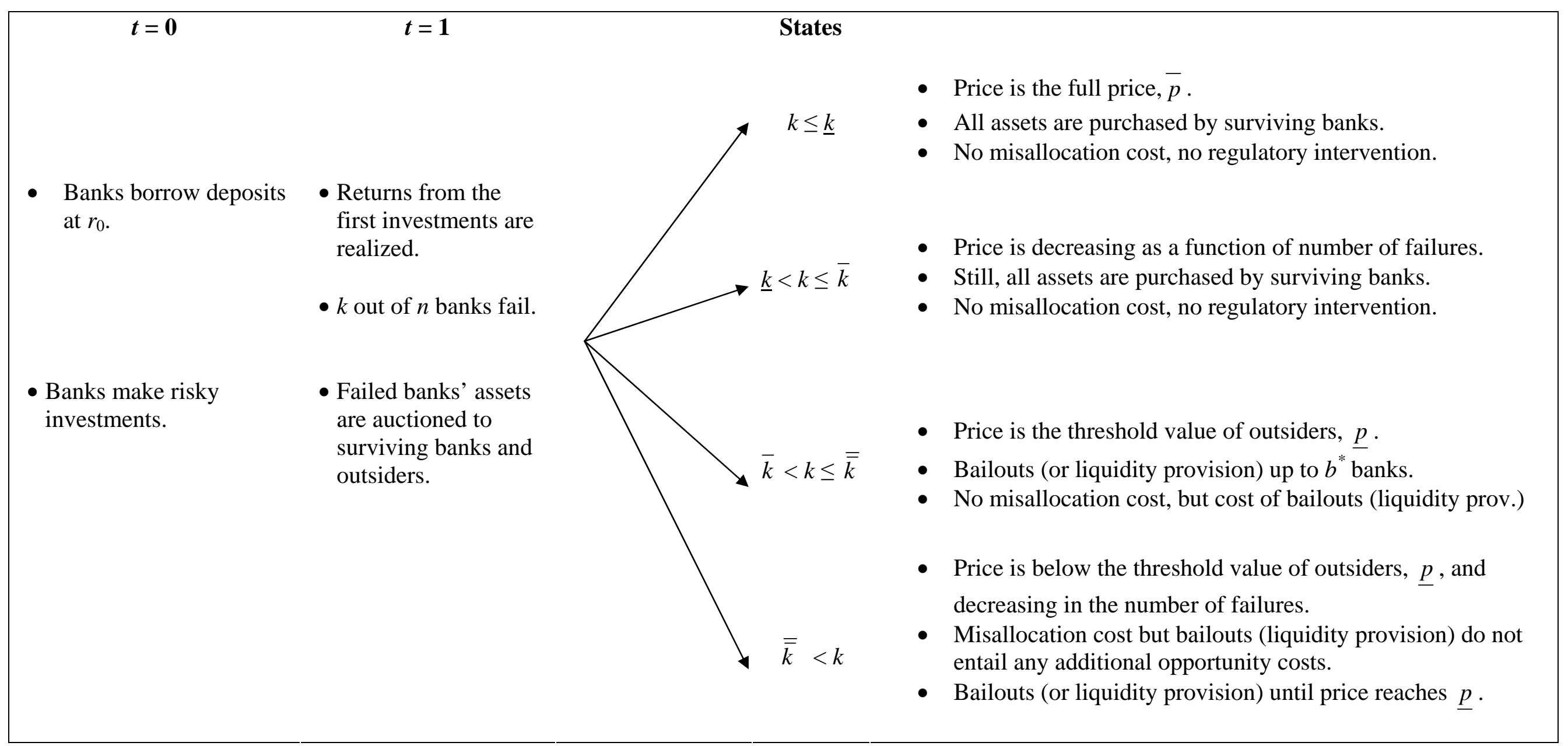

Figure 1: Timeline of the benchmark model. 


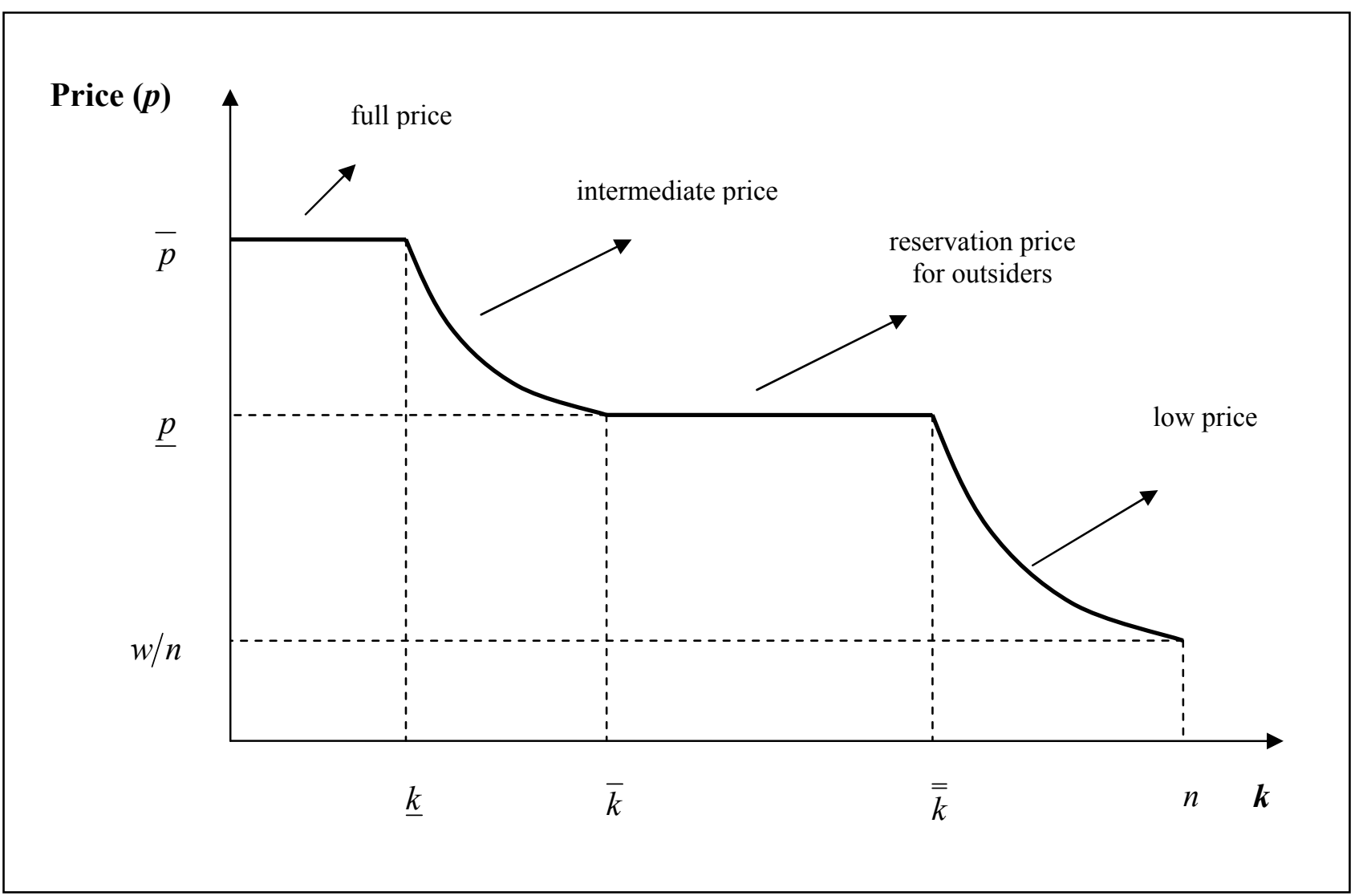

Figure 2: Price with limited outsider funds and no bailouts.

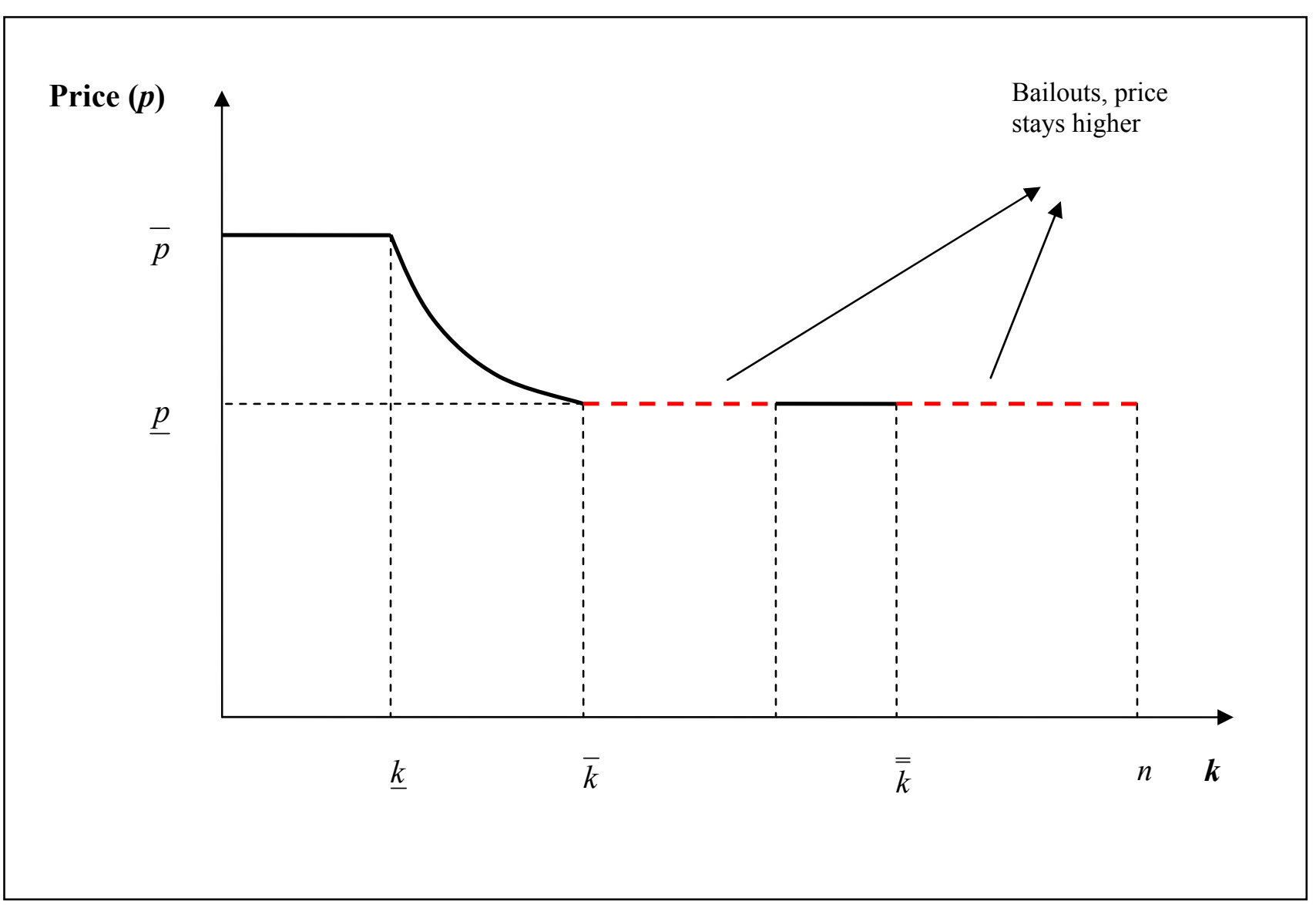

Figure 3: Price with limited outsider funds and bailouts. 


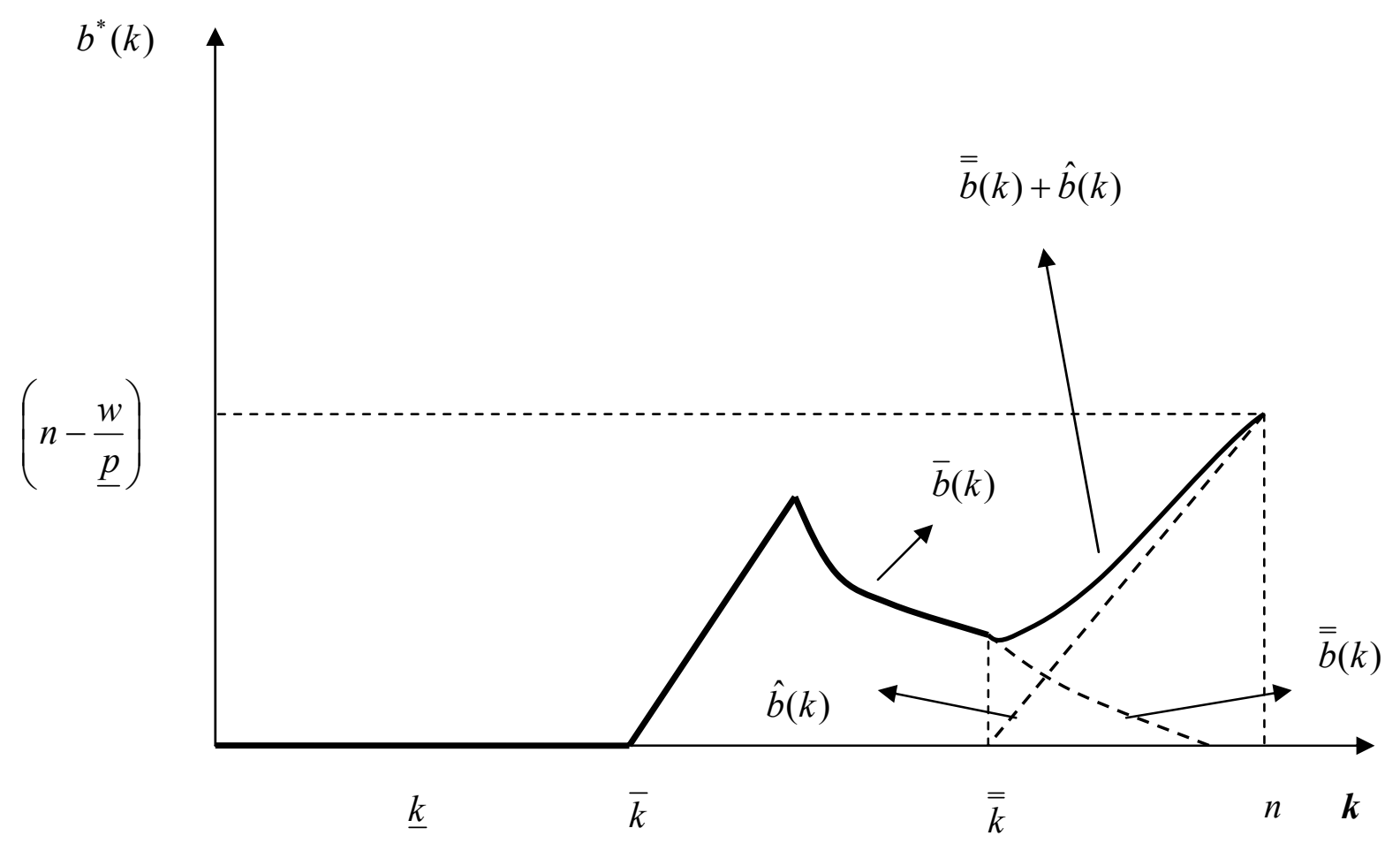

Figure 4: Number of bailouts as a function of number of failures with convex fiscal cost.

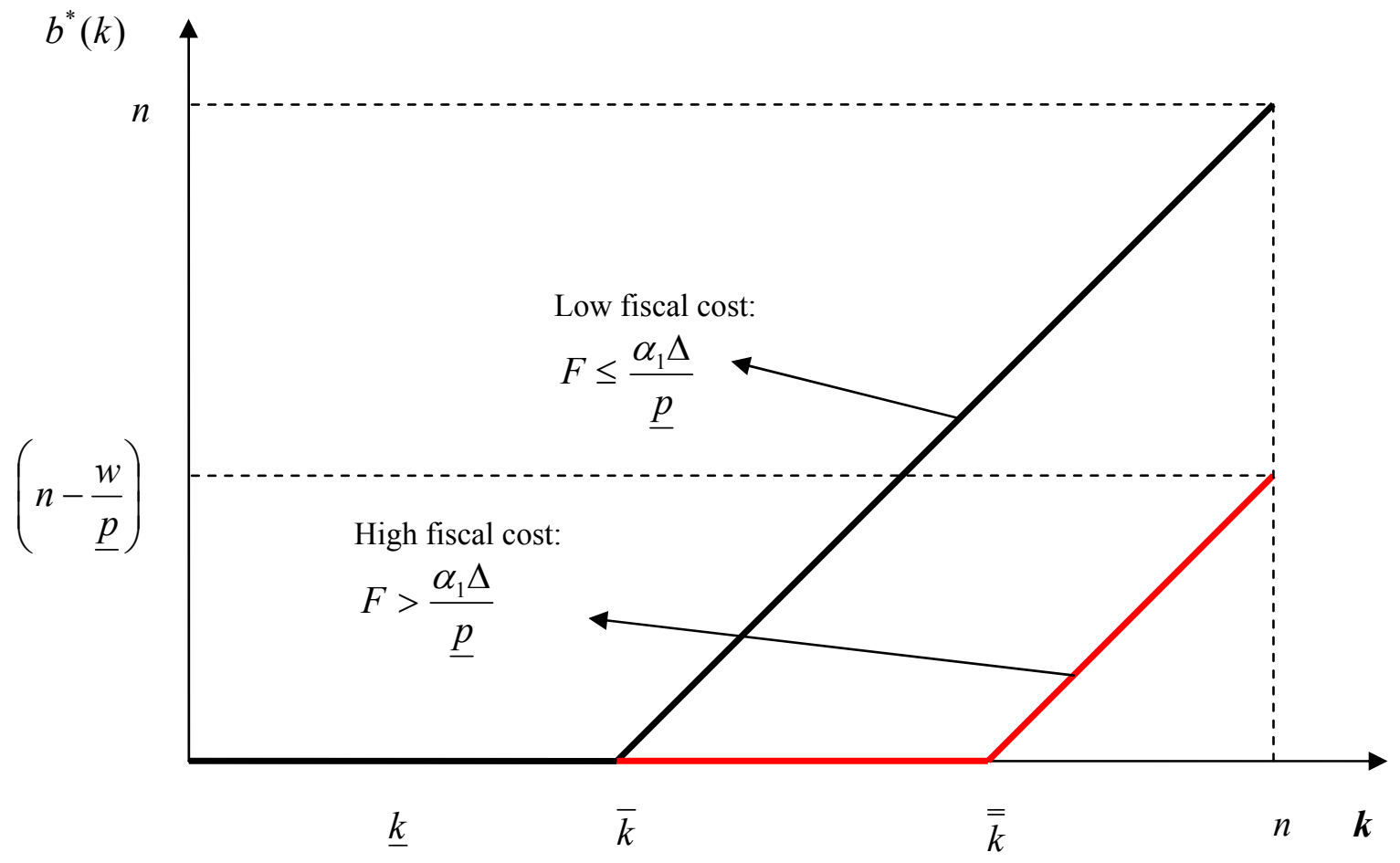

Figure 5: Number of bailouts as a function of number of failures with linear fiscal cost. 


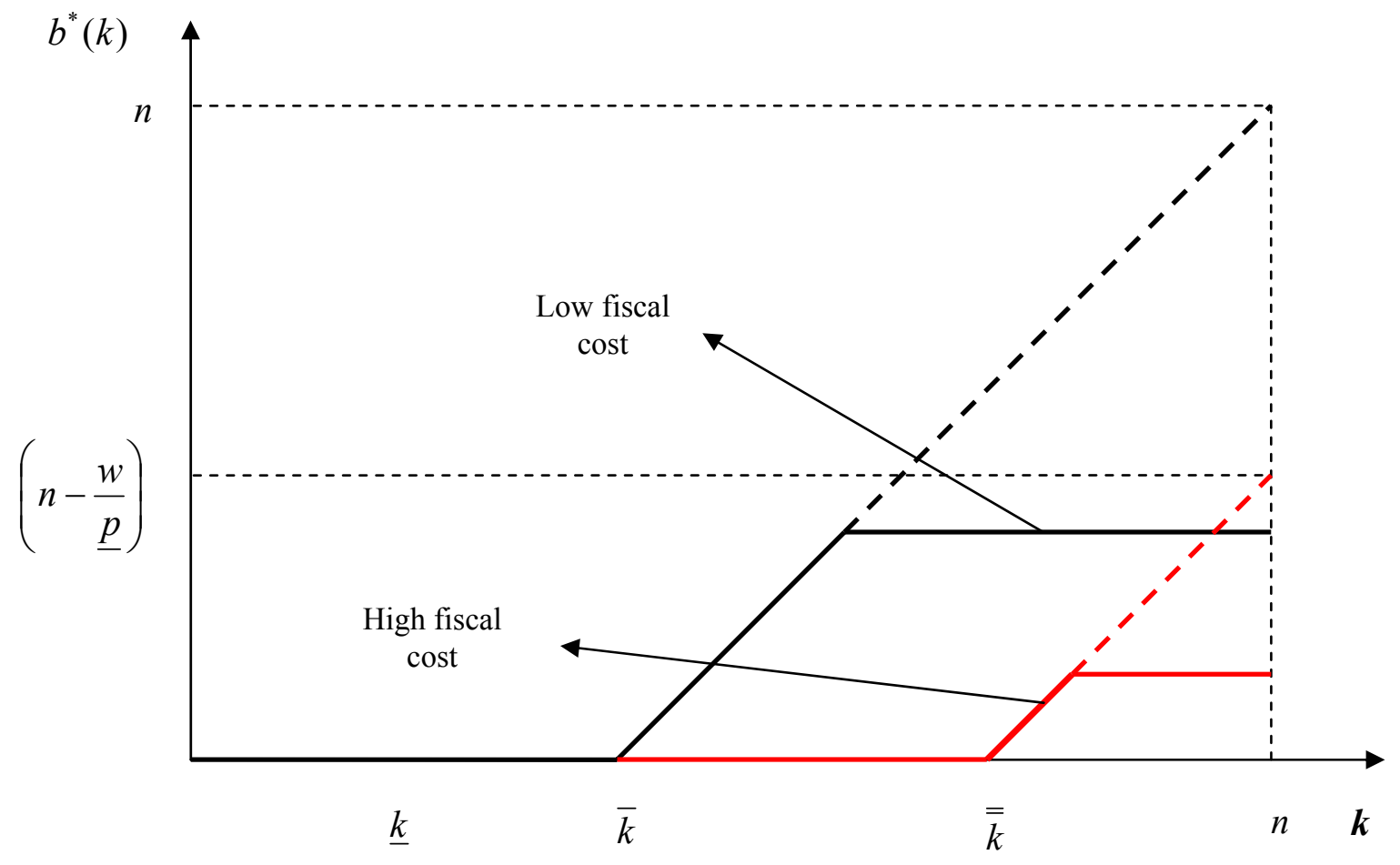

Figure 6: Bailout strategy that implements low correlation.

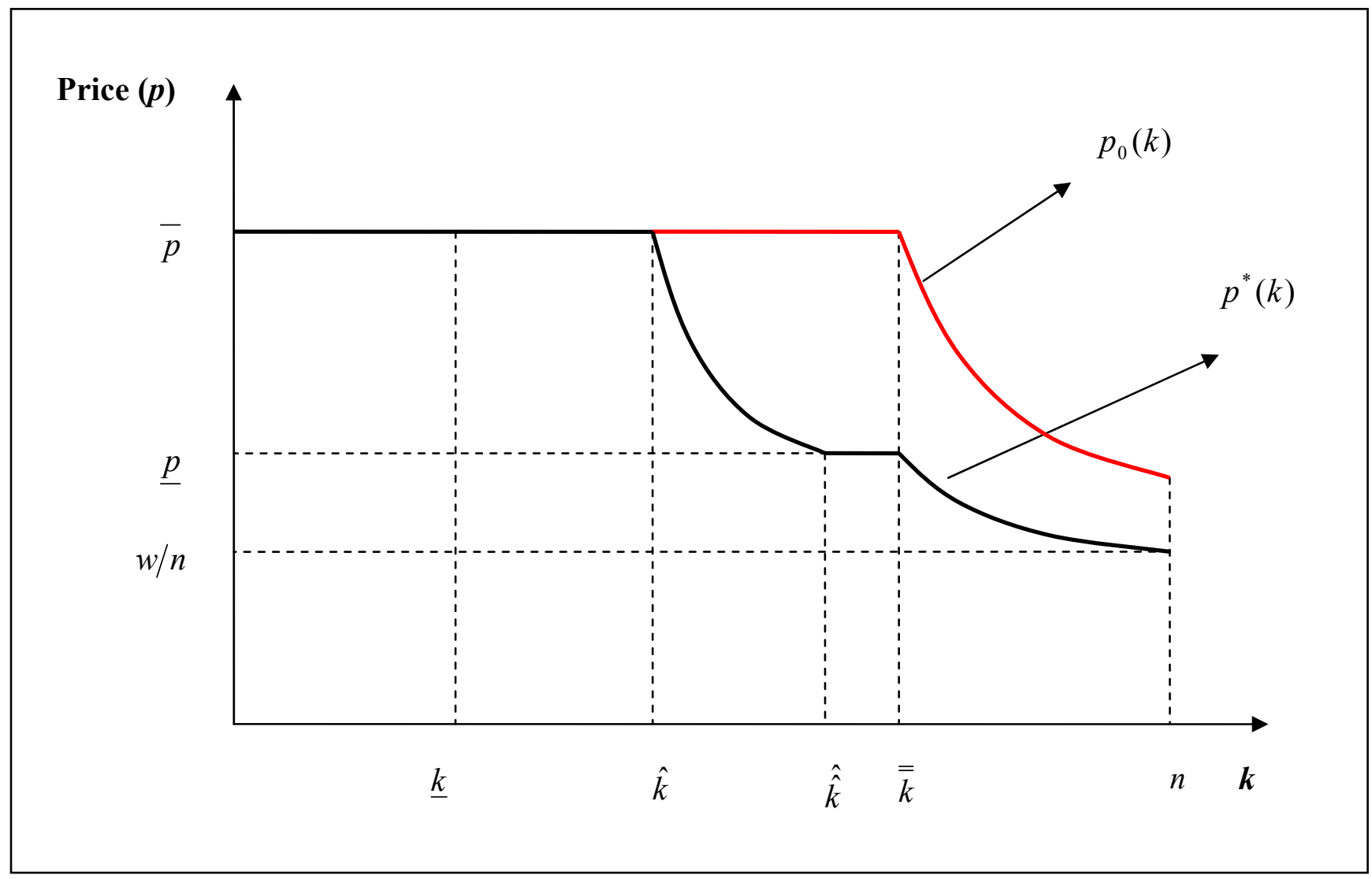

Figure 7: Prices with limited outsider funds and pledgeability (case $(i)$ ). 


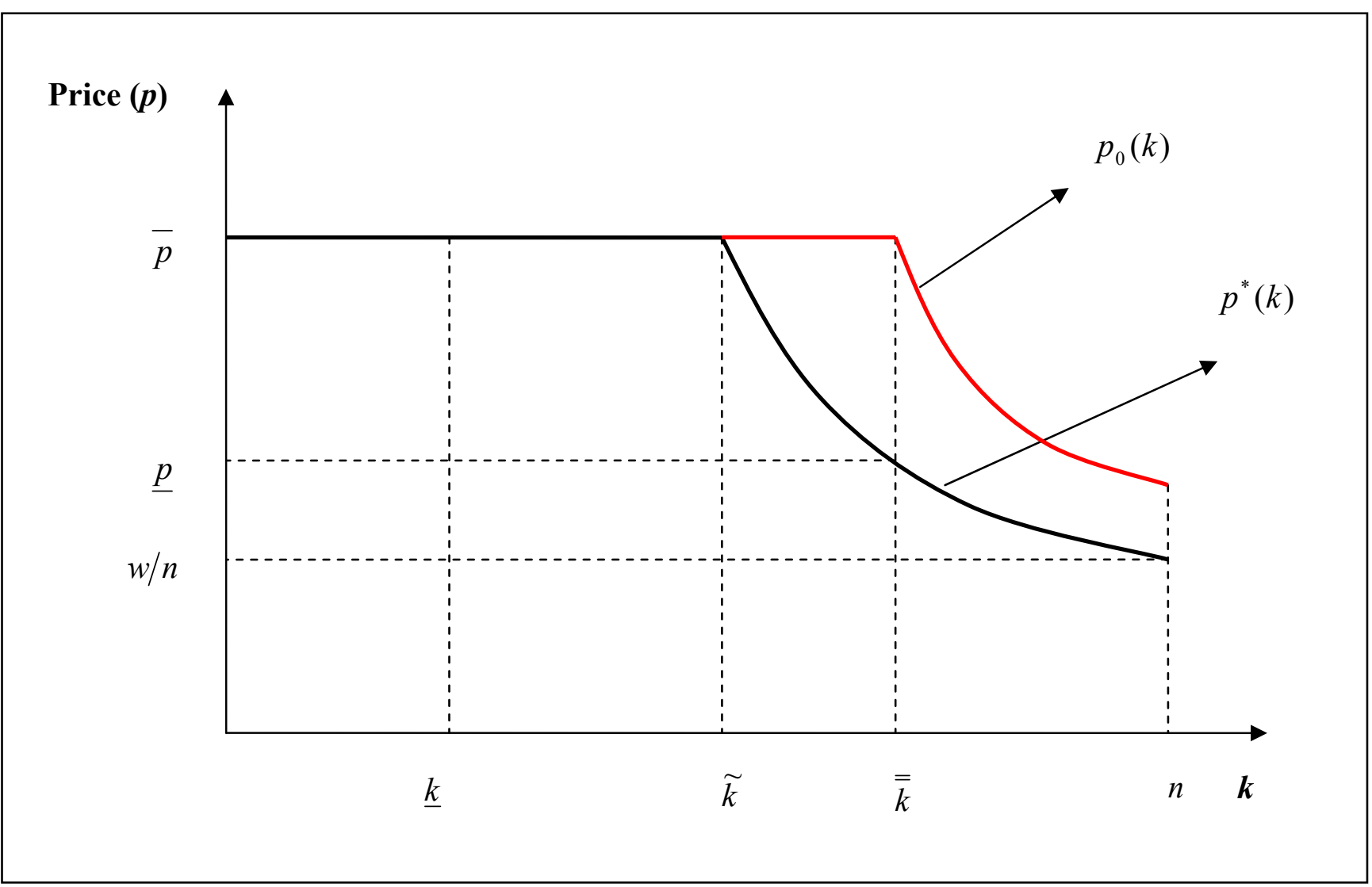

Figure 8: Prices with limited outsider funds and pledgeability (case (ii)).

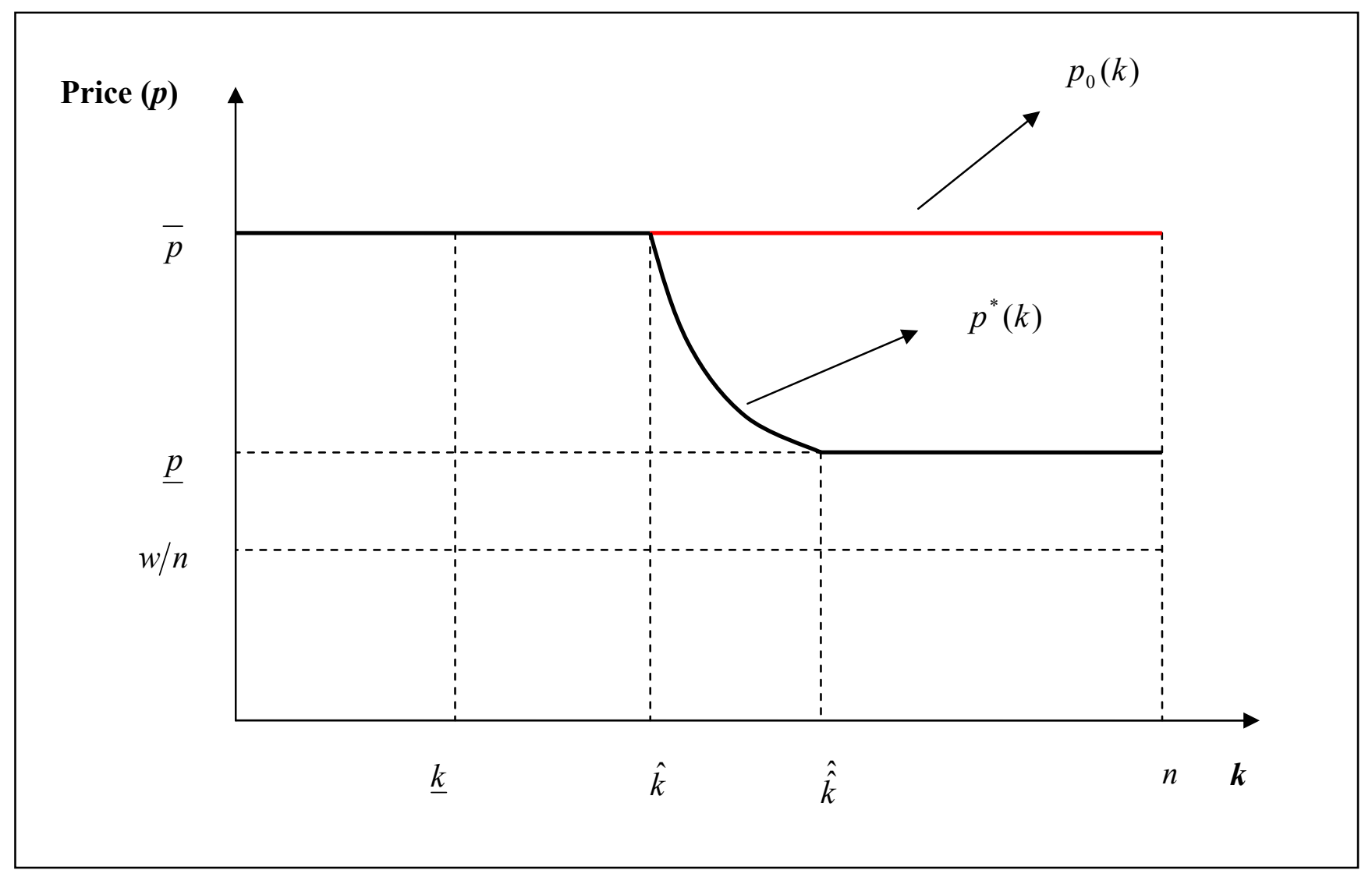

Figure 9: Price with unlimited outsider funds and pledgeability. 


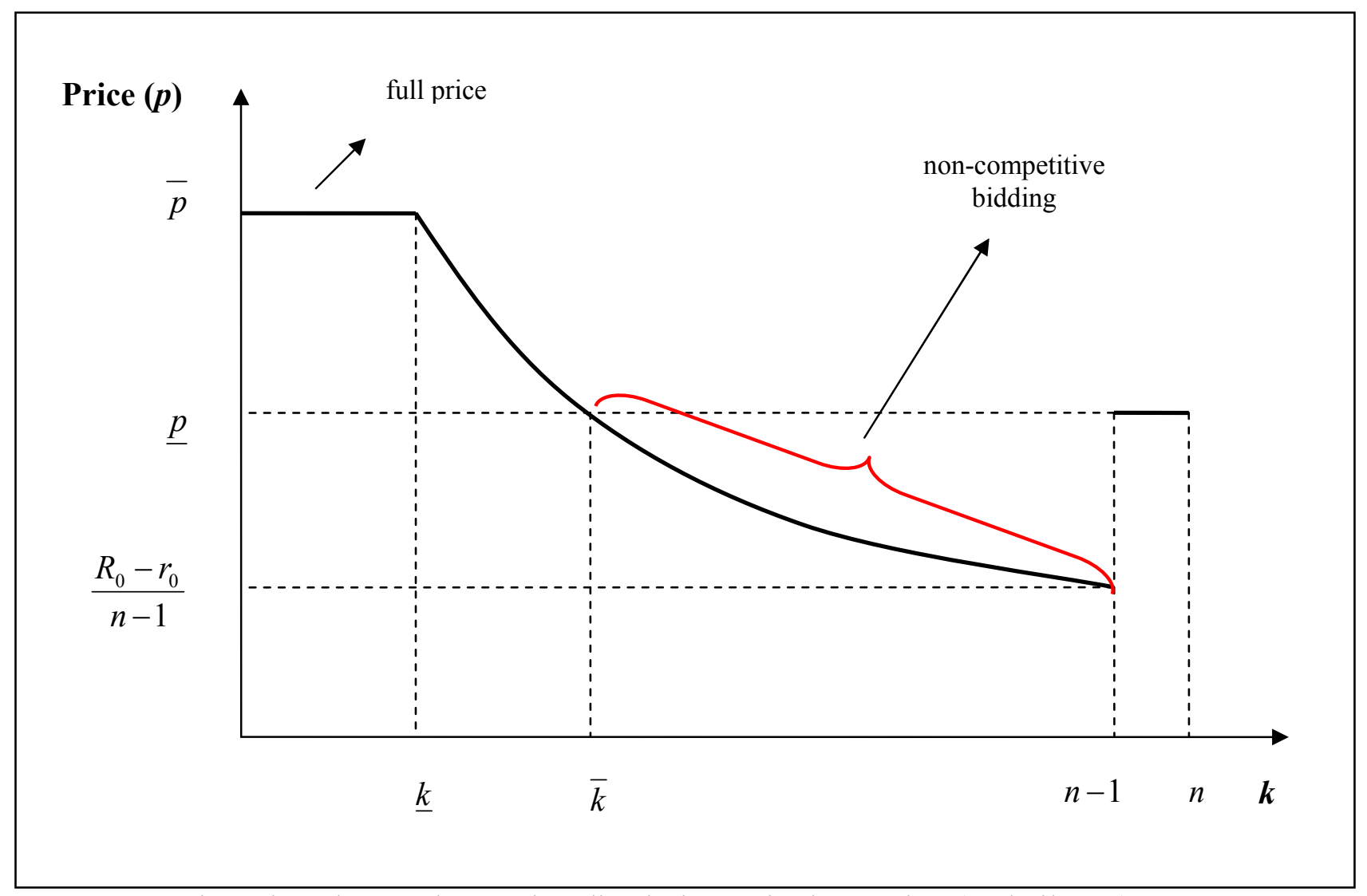

Figure 10: Price when the regulator price-discriminates in the auction (no bail outs). 